\title{
EL MOVIMIENTO MODERNO, EL CORAZÓN DE LACIU- DAD Y LA URBANÍSTICA EN EL CENTRO HISTÓRICO DE ALCOY. UTOPÍAS Y CONCRECIONES ${ }^{I}$
}

\author{
Gabino PONCE HERRERO \\ Dpto. Geografía Humana. Universidad de Alicante
}

Recibido: $12 / 09 / 2013$

Aceptado: 07/12/2013

RESUMEN: La ciudad de Alcoy, de larga tradición industrial en los ramos del textil hogar y la papelería, entró en crisis en los años 1970 como consecuencia de la reconversión industrial hacia nuevas tecnologías y por la deslocalización. Los viejos barrios obreros del centro histórico colapsaron por graves problemas estructurales y sociales. Las primeras tímidas propuestas se centraron en la catalogación de los edificios de mayor valor y en su protección pasiva. En la segunda mitad de los años 1980, en el contexto de las estrategias desarrolladas en algunas ciudades europeas de recuperación de sus espacios centrales, la concordancia política entre las tres administraciones públicas implicadas (estatal, autonómica y municipal) propiciaron un ambicioso programa de renovación integral de la ciudad (Plan ARA con objetivos sociales, funcionales y morfológicos) para convertirla en capital de las comarcas centrales de la Comunidad Valenciana. El paquete de medidas se inspiraba en los principios sociales y funcionales del Movimiento Moderno y, en concreto, en las propuestas para recuperar el corazón de las ciudades. Por su radicalidad frente a las propuestas conservacionistas y pasivas vigentes, desataron un notable debate científico y ciudadano, saldado en beneficio de políticos y técnicos impulsores del Plan ARA. El cambio de signo político en las administraciones cooperantes y la asunción del paradigma neoliberal trastocaron la mayor parte de las propuestas, reorientadas hacia la mera sustitución de viejas viviendas por otras nuevas de promoción privada, tras un largo periodo de interrupción y parálisis, que desvió los objetivos privados y públicos hacia otros ámbitos urbanísticos. Se analiza el proceso teórico y técnico de concreción de las primeras propuestas y los cambios de paradigma, para valorar finalmente los logros alcanzados y el conocimiento empírico resultado de la larga gestión, para conocer sus posibilidades de transferencia hacia otras ciudades de características similares.

PALABRAS CLAVE: Renovación de centros urbanos, estrategias técnicas, políticas y ciudadanas en conflicto

1 El presente texto se incardina en el proyecto de investigación Las ciudades españolas en la etapa autonómica (1978-2012). Dinámicas, procesos y políticas (URBSPAIN), financiado por el Plan Nacional de Investigación I+D+i del Ministerio de Economía y Competitividad para el período 2010-2013 (Código CSO 2009-11261-Subpr. GEOG). 
THE MODERN MOVEMENT, THE HEART OFTHE CITY AND URBAN DEVELOPMENT IN THE HISTORICAL CENTRE OF ALCOY. UTOPIAS AND SPECIFICATIONS

ABSTRACT: The city of Alcoy, with a long industrial tradition in the area of household textile and stationery, went into crisis in the $1970 \mathrm{~s}$ as a consequence of industrial restructuring towards new technologies and relocation. The old working-class neighbourhoods of the historical centre collapsed due to serious structural and social problems. The first timid proposals focused on the cataloguing of the most valuable buildings and their passive protection. In the second half of the 1980 s, in the context of strategies developed in some European cities to restore their central areas, the political concordance between the three public administrations involved (state, regional and local) brought about an ambitious programme for the city's comprehensive renovation (ARA plan with social, functional and morphological objectives) in order to turn it into the capital of the Valencian Community's central regions. The measure package was inspired by the social and functional principles of the Modern Movement and, specifically, by the proposals to restore the hearts of cities. Due to their radicalism compared to conservationist and passive proposals in force, they triggered an important scientific and citizen debate, settled for the benefit of politicians and technicians who promoted the ARA Plan. The change of political sign in the cooperating administrations and the assumption of the neoliberal paradigm disrupted most proposals, reoriented towards the mere replacement of old housing with new private developments, after a long period of interruption and paralysis, which diverted private and public objectives towards other urban development areas. The theoretical and technical realisation process of the first proposals is analysed, together with the paradigm changes, in order to eventually assess the achievements obtained and the empirical knowledge resulting from the long process, to know the possibilities of transferring it to other similar cities.

KEYWORDS: Renovation of urban centres, technical strategies, policies and citizens in conflict

\section{INTRODUCCIÓN}

Como en otras ciudades industriales europeas, los barrios históricos de Alcoy experimentaron en los años 1960 y 1970 graves problemas de deterioro físico y social. Identificada por el Gobierno autónomo como una potencial capitalidad de un territorio valenciano reorganizado a partir de comarcas, las propuestas de recuperación de la vieja ciudad industrial se centraron en la cualificación de las funciones, el hábitat y la morfología. Del gran paquete de intervenciones urbanísticas, las más señeras se propusieron para su centro histórico, abriendo un notable debate científico y ciudadano sobre los criterios de intervención en el centros histórico, del que salió victoriosa la renovación sobre la rehabilitación, pero sin el necesario apoyo social.

\section{METODOLOGÍA}

Se propone un análisis deductivo que parte de las referencias esenciales de los paradigmas del Movimiento Moderno, recogidos en los sucesivos Congresos 
Internacionales de Arquitectura Contemporánea, y en su traslación en el tiempo y lugar, propuestas para España por Solà- Morales (SolÀ-Morales, 1997 y 1999), entre otros, para interpretar su concreción en el proceso de renovación absoluta propuesto para el centro histórico de Alcoy en la etapa autonómica. La ciudad experimentó en sus barrios el debate urbanístico suscitado en los años 1980 y 1990 a raíz de la aparición del morfologismo -tipologías- desarrollada en España por la Urbanística, y el debate que enfrentaba al plan con el proyecto (las escuelas de Madrid y de Barcelona) y los nuevos criterios de intervención en la ciudad consolidada -centros históricos- (SAINZ, 2006) por lo demás muy común en las ciudades europeas en procesos de reconversión industrial y renovación de las áreas fabriles y obreras (RINCÓN, 2005). Se conjugaban en las propuestas para Alcoy los aspectos formales del diseño y la racionalidad científico-técnica adaptada al sitio y al momento como fórmulas de renovación social y funcional.

La hipótesis mantenida es que las grandes transformaciones afectan muy sensiblemente al alma de las ciudades y a las formas de vida tradicionales y que sus potenciales beneficios llegan sólo si el plan es minucioso y constante. Objetivo central es demostrar como el apoyo ciudadano es a la larga tan decisivo como el apoyo político. Otros objetivos son identificar los agentes clave en el proceso, los cambios de paradigmas y sus consecuencias y las posibilidades de que la experiencia sea transferible a otras ciudades de características similares, con su corolario de buenas y malas prácticas. Para el análisis se ha acudido a las fuentes de información urbanística del Ministerio de Fomento, del Gobierno Valenciano y del Ayuntamiento de Alcoy, a las estadísticas demográficas y de viviendas del INE y del IVE y a las entrevistas y encuestas cualitativas.

\section{UN AMBICIOSO PROGRAMA FALLIDO}

\section{III.1 Un centro histórico de alto valor patrimonial}

La ciudad de Alcoy experimentó los beneficios de la Revolución Industrial en el s. XVIII y alcanzó gran prosperidad en el s. XIX merced a la industria textil. El crecimiento, después de una primera "ampliación geométrica del plano", exigió la aprobación en 1878 de un Plan de Ensanche, que permitió el crecimiento ordenado de las clases medias y de la burguesía, mientras las fábricas se amontonaban en el fondo de los dos ríos que ciñen la ciudad histórica (ríos Barxell y Molinar) y generaron la primera fuerza motriz de la industria textil. Por su parte, el proletariado se hacinaba en el estrecho callejero del centro histórico, donde 
los edificios, de adobe y tapial, crecían hasta siete y ocho plantas de altura por la simple añadidura de nuevas viviendas encima de la anterior.

En ese callejero histórico, se ha reproducido hasta los años 1960 el alojamiento de varias familias en una sola vivienda, alquilando una habitación para dormir (toda la familia), con derecho al uso de los espacios comunales (cocina, comedor, retrete). Fueron las conocidas cases de Claus -casas de llaves- donde cada habitación tenía una llave para preservar la intimidad de la familia instalada en ella. Ese reparto interno, unido a los fuertes desniveles del suelo, determinaba que el reparto de las dependencias de la vivienda se hallase con frecuencia a diferente nivel y se organizasen de manera helicoidal en torno al eje de la escalera. Se trata de aspecto simbólico recogido en el Barri de La Sang, como forma de enraizar y contextualizar los criterios de la arquitectura contemporánea $-\mathrm{y}$ del formalismo- en el sitio concreto del centro histórico de Alcoy.

El Plan General de Ordenación Urbana de 1957 ampliaba el radio del Ensanche para la creación de ciudad nueva, contribuyendo al despoblamiento del centro histórico, aunque éste seguía manteniendo su función de almacén de mano de obra, proletariado y subproletariado, engrosado por la llegada masiva de inmigrantes en la etapa del desarrollismo. La incomprensible pérdida de entidad de las posteriores figuras de ordenación urbana (Normas Complementarias de 1973 y Normas Subsidiarias de 1981) para una ciudad tan dinámica, tampoco trazaron ninguna propuesta sobre ese espacio histórico, convertido de hecho en ámbito de infraviviendas, con fuertes densidades y carencias dotacionales de todo tipo.

La población de ese espacio central fue en aumento hasta 1955, alcanzando los 12.701 habitantes, que suponían aproximadamente el 30\% del total de la población de Alcoy, hacinada hasta alcanzar densidades de 858 hab./Ha en ese año. A partir de esos momentos, la construcción de nuevas barriadas obreras en el extrarradio del Ensanche (mientras éste no terminaba de ocuparse), ocasionó una pérdida constante de población en el centro, que descendió hasta los 2.808 habitantes en 1986. La renovación de buena parte del centro histórico y la construcción de nuevas viviendas han permitido recuperar población en las últimas décadas: 4.391 habitantes en 2001 y 4.809 habitantes en 2011, que suponían el $8 \%$ del total de los 61.093 habitantes de la ciudad en ese año.

\section{III.1.a. La concreción de un conjunto histórico-artístico}

El proceso de modernización social inherente a la temprana industrialización de la ciudad a lo largo del siglo XIX puso fin al antiguo régimen, dando paso a dos nuevas clases sociales emergentes, la burguesía industrial y comercial y el proletariado industrial, que acabarían segregándose conforme a las claves del mer- 
cado del suelo. Como en otras ciudades, la burguesía impulsaba la redacción de un plan de ensanche pero no se trasladaba a él. De hecho, pugnaba por arracimarse en los espacios simbólicos del poder civil y religioso de la ciudad, levantando sus palacetes entorno a la Plaza de España, donde se halla el Ayuntamiento neoclásico del s. XIX (sobre un convento gótico desamortizado del que queda algún restos) y la principal iglesia de la ciudad, la Arciprestal de Santa María (barroca con añadidos neoclásicos). De esa plaza parten los antiguos caminos carreteros hacia Alicante (actual Calle San Nicolás) y hacia Valencia y Madrid (actual Calle País Valencià) con una sección de $7 \mathrm{~m}$, frente a los $3 \mathrm{~m}$ de media del resto del callejero envolvente, donde se suceden, todavía hoy, las casonas y los apartamentos decimonónicos de la burguesía, con locales comerciales en la planta baja.

Se trata de ejes que han mantenido su valor simbólico por hallarse en el circuito de las principales celebraciones festivas de Alcoy: las fiestas de Moros y Cristianos y la Cabalgata de Reyes Magos. Cumplen así un papel de escenario icónico que explica el mercado de alquiler de balcones para presenciar esas celebraciones (alrededor de $500 €$ /balcón en 2012) y, también, la peculiar distribución de las ayudas para la rehabilitación de viviendas procedentes del Instituto Valenciano de la Vivienda (IVVSA) en su mayor parte convergentes en esos ejes.

Son edificios por lo general de buena factura, con uso (aunque sea circunstancial) y, por tanto, bien conservados, fruto de las tres corrientes arquitectónicas que dejaron su impronta en la ciudad durante el s. XIX:

- el academicismo, con ejemplos neo-renacentistas y neo-clásicos, que revivió tras la guerra civil y se mantuvo hasta los años 1950, y dejó los principales edificios públicos como el Ayuntamiento, el Banco de España y la Cámara de Comercio e Industria (antigua Banca Vicens),

- el modernismo, con dos tendencias en pugna con interesante trasfondo ideológico: el art nouveau naturalista y ostentoso -propio de nuevos ricos- y la sezession vienesa, más abstracta, simbólica, discreta e intelectual,

- el eclecticismo, entendido como programa arquitectónico que mantenía la configuración y distribución antiguas de los edificios, con una fachada superpuesta de aires modernistas; estas viviendas en bloque, construidas por maestros de obra, dieron morada al proletariado emancipado que ascendía a una exigua clase media.

Por su parte, el proletariado configuraba una potente ciudad de adobe, interesante en su conjunto, pero configurada por una insana acumulación de infraviviendas, como describe la Memoria Justificativa del Ensanche en 1878: ... No ignora la Corporación municipal la situación de esta población enclavada entre dos barrancos, y que, falta de medios de extenderse, habia de buscar su compen- 
sación en la elevación de los edificios... Tal estrechez, no há podido menos de originar también una subdivisión ilimitada de los edificios de los particular es, hasta el punto de que en gran parte de ellos, el número de sus propietarios, se cuenta por el número de sus pisos ó tal vez de sus habitaciones... parecen castillos suspendidos á cuarenta y mas metros, con cinco y seis pisos de habitaciones estrechas, donde se hacinan numerosas familias que no disponen de la cantidad de aire y luz que necesitan para vivir... de una tierra que les dá para vivir poco mas terreno del que ocuparan el dia de su muerte... Es la ciudad que se hunde (por sí sola) o se derriba a instancias de expedientes de ruina, pero que sigue acogiendo a los segmentos sociales más desfavorecidos, en las mismas condiciones que las descritas en el s. XIX.

La Constitución de 1978 (art. 46) consagraba la obligación de las administraciones públicas de garantizar la conservación del patrimonio histórico artístico de los pueblos de España, señalando la posición preminente del Estado y de los Gobiernos autonómicos, y la posición subordinada de los ayuntamientos. En 1982 se aprobaba el Estatut d'Autonomía de la Comunidad Valenciana y con él se desencadenaba una oleada de declaraciones de conjuntos histórico-artísticos, con el doble objetivo de buscar las raíces del "nuevo país en construcción" y de garantizar la conservación del patrimonio valenciano muy afectado por las fuertes transformaciones derivadas del desarrollismo incontrolado de las décadas precedentes. Entre otros, por Real Decreto 3945/1982 todo el centro histórico de Alcoy fue declarado conjunto histórico-artístico (conforme con los principios de la Ley de Patrimonio Histórico-Artístico Nacional de 1933), lo que de hecho suponía una llamada al orden al Ayuntamiento para que procediese a desarrollar instrumentos propios que garantizasen su conservación. El proceso se repetía en las demás comunidades autónomas, no sin problemas de coordinación y de criterios, de forma que se hizo precisa la redacción de la Ley 16/1985 de Patrimonio Histórico Español, luego sustituida en la Comunidad Valenciana por la Ley 4/1998 del Patrimonio Cultural Valenciano, que convertía los conjuntos histórico-artísticos en Bienes de Interés Cultural (BIC), entre ellos el de Alcoy.

III.1.b. Los criterios posibilistas (historicistas) de los primeros planes de protección y rehabilitación

La declaración como conjunto histórico-artístico activó de hecho la voluntad municipal para elaborar un Plan de Rehabilitación del Centro Histórico, redactado por el arquitecto urbanista Manuel Vidal (natural de Alcoy y coautor del Barri La Sang), que fue presentado en 1984. Sin embargo, no pudo ser legalizado ya que la ciudad había cambiado su Plan General por unas absurdas Normas Subsidiarias aprobadas en 1981, sin capacidad legal para amparar un Plan Especial 
de centro histórico. Esas y otras cuestiones animaban la voluntad de redactar un auténtico plan general que diese respuesta a las necesidades de una ciudad tan potente y dinámica como Alcoy. Así, entre tanto y para dar respuesta a las demandas del movimiento vecinal del centro histórico, aquejado por los problemas endémicos de infravivienda y carencias dotacionales, se encargaba al estudio de Carlos Ferrán Alfaro (Madrid) un Inventario de Edificación Zona Histórico Artística de Alcoy que se presentaba en 1984, pero seguía careciendo de valor jurídico.

El mismo estudio presentaba en 1986 un nuevo Plan Especial de Reforma Interior del Casco Histórico de Alcoy, como contexto necesario para el Inventario de 1984, que no encajaba en el primer plan de Manuel Vidal de 1984. El nuevo PERI del Casco Histórico, de marcado carácter conservacionista y proteccionista, centraba la atención en la conservación de los edificios, limitando los usos y funciones potenciales de los mismos. De hecho, seguía la línea de pensamiento posibilista, que defendía el valor de cada una de las aportaciones históricas a la ciudad (historicismo) coherente con las sucesivas declaraciones de patrimonio de la UNESCO y sus recomendaciones (Carta de Venecia de 1964, Carta Europea del Patrimonio Arquitectónico de 1975) que hacían hincapié en la conservación integrada del patrimonio arquitectónico, señalando que "no sólo está formado por los monumentos más importantes, sino también por los conjuntos que constituyen las ciudades tradicionales en sus entornos". Esa sería la doctrina oficial del Gobierno Valenciano para intervenir en los centros históricos, sólo alterada y con matices a finales del siglo XX, como recoge el informe Intervenciones en centros históricos de la Comunidad Valenciana, de 2001, encargado por la Consellería d’Obres Públiques, Urbanisme i Transports (Coput, 2001).

Pero el nuevo PERI conservacionista no sería legalizado hasta la aprobación en 1989 del Plan General de Ordenación Urbana, en unos momentos convulsos para la ciudad, muy aquejada por la crisis industrial y la pérdida de habitantes y funciones deslocalizados en beneficio de municipios vecinos. Lo que ponía en cuestión las indicaciones del PERI que, de hecho, se soslayaban para "intervenir de urgencia" en diferentes ámbitos del callejero histórico sin mediar directrices claras.

\section{III.2 El cambio de paradigma y la asunción de los criterios positivistas para renovar el centro histórico de Alcoy}

Evidencia de la crisis de criterios de la Administración local es que, en 1987 se aprueba un Proyecto de Urbanización General para el Raval Vell, el Raval Nou y La Sang, al margen del PERI de 1986, bajo la premisa de la renovación y la construcción de viviendas nuevas, no tanto por consideraciones conceptua- 
les, como por la imposibilidad de mantener en pie los edificios construidos en adobe y tapial y sin cimentación.

En 1989 se aprobaba un PGOU, redactado por José Antonio Torroja (Madrid), que introducía importantes elementos de ambigüedad en sus determinaciones sobre el centro histórico que, al tiempo que daban cobertura legal a las precedentes, hicieron posible las posteriores actuaciones en el mismo sin que se llegase a redactar un plan especial. El nuevo PGOU delegaba la ordenación del centro histórico a "la redacción de un plan especial integral del Casco Histórico a redactar en el plazo de un año a partir de la aprobación definitiva del presente PGOU' (Torroja, 1989), circunstancia que nunca se produjo. Sin embargo, el "Anexo 1. Ordenación de Casco Antiguo" del mismo PGOU abría la posibilidad de ejecutar proyectos de reparcelación, urbanización y edificación (Art. 5) y explicitaba que sólo sería necesario un plan especial cuando las determinaciones del plan general "no hubieran alcanzado el suficiente grado de pormenorización".

El mismo Anexo 1 exponía las claves que permitirían al Ayuntamiento convertir las viejas manzanas edificadas en suelo urbano público, al catalogar como "solar sin edificar... todos los edificios ilegales, los que se hallen por debajo del coeficiente de edificabilidad asignado a la zona, las construcciones provisionales, las construcciones paralizadas, las construcciones ruinosas y las derruidas al menos en el 50\% de su volumetría". Al tiempo que señalaba el límite mínimo de la parcela edificable en $250 \mathrm{~m}^{2}$, cuando la media del centro histórico no llega a los $100 \mathrm{~m}^{2}$, lo que obligaba a una concentración parcelaria y, con ella, a la demolición de los viejos y estrechos edificios.

El PGOU recogía también en su Catálogo de Edificios Protegidos el Inventario de 1984 elaborado por Carlos Ferrán, que sería ampliado. En él se indican las zonas de alto valor y, por ello, las más protegidas, que se circunscribe a las fachadas (y no al conjunto de los edificios) del eje burgués antes señalado (calles San Nicolás, San Lorenzo, Santo Tomás y País Valencià, junto con la Plaza de España), de hecho casi las únicas protegidas realmente.

Tal como se indicaba en el PGOU, en 1989 se inició la redacción de un nuevo Plan Especial de Reforma Interior para el Casco Antiguo, explícitamente encargado para superar las restricciones conservacionistas de los anteriores no aprobados, y para dar salida a las ejecuciones en marcha en los barrios de la ciudad antigua. El nuevo PERI fue encargado a Carlos Merí Cucar (Valencia), fue aprobado inicialmente y expuesto al público, que lo rechazó frontalmente por ser considerado demasiado renovador y ajeno al paisaje urbano tradicional. Entre las cuestiones más criticadas se hallaba la limitación del fondo edificable para crear patios de manzana que, además, debían abrirse a las calles para que el centro 
histórico contase con nuevas zonas verdes (las de los patios de manzana), lo que chocaba con la parcela tradicional alcoyana, en forma alargada con unos 4 metros de fachada y entre 18 y 20 metros de profundidad, ocupando toda la parcela. De hecho, esa premisa suponía la demolición completa de todas las manzanas del centro histórico. El nuevo PERI incluía un nuevo Catálogo de Edificios de Interés, pero ahora elaborado conforme con los criterios del IV Congreso de Arquitectura Internacional Moderna (CIAM) de 1933-1934, que señala que el edificio histórico debe ser salvaguardado "si no afecta a la vida de la zona", que se deben "destruir los tugurios y convertirlos en zonas verdes" y que "se debe desplazar el centro urbano hacia lugares mejor diseñados".

Presentado y discutido, el nuevo PERI no sería aprobado definitivamente, pero daba igual, ya que los proyectos de ejecución posibilitados por el PGOU abrían el paso a los nuevos criterios renovadores para intervenir en el centro histórico, de manera que el conjunto histórico-artístico fue ordenado conforme con los ambiguos criterios del Anexo 1 del PGOU de 1989, sin figura específica de planeamiento, pese a valor patrimonial y a la importancia renovadora de los proyectos previstos.

Entre otras destacadas cuestiones, merece ser señalado que con esa decisión local se invertía el principio de preminencia del Estado y del Gobierno autonómico en las tareas de conservación del patrimonio (sancionando los planes), y era la Administración local -el Ayuntamiento de Alcoy- la que asumía las competencias por el simple pero eficaz procedimiento de crear una indefinición legal en el centro histórico, todavía no resuelta (como se verá). Así, se desarrollaban el Proyecto de Urbanización General para los barrios del Raval Nou, La Sang y del Raval Vell, todos del centro histórico.

Mediante proyectos de ejecución (al amparo del Anexo 1 del PGOU) se procedía a demoler toda la zona de Buidaoli (el núcleo genético de la ciudad), a crear suelo de propiedad municipal, a reparcelar y a la rectificación y ampliación del viario (respetando los edificios catalogados y el lienzo de la muralla aparecido al demoler las viviendas anexadas). Con un proceso que arranca en 1987, promovido por el Ayuntamiento a través del IVVSA, en 1991se entregaban 52 viviendas agrupadas en bloque, de protección oficial levantadas sobre el reorganizado y vacío parcelario de Buidaoli, que sigue vacío. En el mismo año, en el Raval Vell (Plaçeta Les Xiques, Muralla Barbacana), con los mismos procesos y criterios se hacía entrega de otras 40 viviendas, si bien Manuel Vidal, responsable del diseño, proponía que las viejas viviendas anexadas a la muralla fuesen reemplazadas por otras nuevas, también anexadas al lienzo mural. De ese modo, por un lado se mantenía -bajo condiciones de habitabilidad contemporáneas- la "tradicional" 
ocupación de murallas y torres urbanas por el caserío popular. No obstante, por otro lado daría origen a un problema legal sobre la propiedad de la vivienda construida dentro de un BIC -la muralla- de propiedad pública. En 2016 (después de 25 años desde la entrega de las llaves) deberán escriturarse las propiedades, por ello los vecinos se hallan inmersos en una batalla legal para ser reconocidos como propietario de unas viviendas que no aparecen ni en el Catastro de Urbana (donde están catalogadas como solares), ni en el Registro de la Propiedad.

Pensadas y ejecutadas antes del Plan ARA (presentado en 1991), la propuestas de viviendas sociales para segmentos muy desfavorecidos han sido un importante lastre en el desarrollo de los objetivos más cualitativos de la etapa posterior. Ambos grupos de viviendas -Buidaoli (Torre de Fraga) y Ravall Vell (Plaçeta Les Xiques, Muralla Barbacana) se han convertido en focos de actividades delictivas. Algunos vecinos entrevistados señalan como "algunos inquilinos de carácter social sólo pagan, si lo hacen, $10 €$ al mes de alquiler" y otros compradores iniciales abandonaron el barrio perdiendo el millón de pesetas que dieron de entrada, por un piso de $63 \mathrm{~m}^{2}$ de media (complementado con una cuota mensual -de $200 €$ en la actualidad- durante 25 años). Esa cuestión social ha sido determinante en la falta de interés y el progresivo abandono del centro histórico. De hecho, afectó notablemente a la promoción del Barri La Sang, de más calidad arquitectónica (planeado por Solá-Morales y Manuel Vidal -con otros-, levantado entre 1991 y 2001 y entregado en 2004), ya que los potenciales compradores se retrayeron ante la posibilidad de compartir barrio con los mismos segmentos sociales que pululaban por las anteriores promociones públicas de viviendas.

En 1990 se aprobaba el Programa de Renovación Urbana de La Riba (otro de los barrios del centro histórico), pero su desarrollo quedaría condicionado por el Plan ARA y sus nuevas propuestas más elitistas para esa porción del centro histórico (se superaban los criterios sociales, ante los problemas evidenciados en las primeras actuaciones). La Riba queda entre el eje burgués de San Nicolás y el Río Molinar, y pese a la elevada valoración patrimonial de las fachadas de los edificios, conforme con el Catálogo de Edificios de Interés (PGOU 1989), la propuesta en 2007 se concretó en la sustitución de los viejos edificios (en su integridad) por nuevos bloques de viviendas, que recrean la desigual volumetría y cromatismo del parcelario tradicional, con fachadas que interpretan la tradición vernácula y recrean los balcones miradores para las celebraciones festivas.

El complejo proceso iniciado alcanzaría coherencia en 1991 cuando se presenta el Programa Arquitectura i Rehabilitació a Alcoi -Plan ARA-, que recogía abiertamente el paradigma de la renovación (ante el ya latente estado de ruina e inconsistencia de las construcciones existentes) y sumaba la voluntad de recupe- 
rar el centro histórico a partir de la recualificación del espacio público, de la mano de un nutrido grupo de arquitectos señeros.

\section{III.3 Los "actores-eje" del proceso: ideología y técnica en el debate}

En la secuencia y desarrollo de las actuaciones aparece un conjunto de figuras clave, con especial significado en la orientación de los procesos urbanísticos experimentados por el centro histórico de Alcoy. La conjunción de intereses entre agentes políticos y técnicos resulta reveladora en la explicación cronológica de las actuaciones.

Especial significado alcanza la figura del alcalde José Sanus Tormo, que extendió su mandato entre 1979 y 2000. Ganador de las primeras elecciones municipales democráticas con el PSPV-PSOE, en su segundo mandato procedió al encargo de dos planes de actuación consecutivos para el centro histórico (1984 y 1986 ambos sin aprobación definitiva) como respuesta inmediata a las demandas del movimiento ciudadano para recuperar el depauperado centro histórico y sus barriadas de obreros. Se trata de planes conservacionistas, conforme con la opinión ciudadana y las corrientes urbanísticas más en boga del momento.

Es en su tercer mandato (1987-1991) cuando se observa el giro hacia la renovación, evidente en el encargo del PGOU (aprobado en 1989) al equipo de urbanistas dirigido por José Antonio Torroja, vinculado al Movimiento Moderno. Así, en el prólogo del Plan ARA (1991) el Alcalde defendía los dos grandes principios de la nueva etapa: "superar la actitud del conservadurismo de la ciudad antigua y controlar todo el proceso desde los poderes públicos" (COPUT, 1991).

Los fondos llegaron desde el Instituto Valenciano de la Vivienda (IVVSA), organismo público, creado en 1987, que depende de la Consellería de Obres Públiques, Urbanisme i Transports -COPUT-, y tiene por objeto la gestión integral de las estrategias de vivienda pública de la Generalitat Valenciana, con un marcado perfil social en sus actuaciones, siempre sobre suelo y viviendas del patrimonio público de la Generalitat Valenciana. Era pues preciso que el centro histórico de Alcoy se convirtiese en suelo público para recibir la ayuda del IVVSA, lo que explica el esfuerzo desarrollado desde el Ayuntamiento para declarar en ruina, demoler y expropiar viejos edificios.

Otras interpretaciones políticas llegaban desde el Gobierno valenciano para justificar las grandes inversiones públicas en la ciudad, como su elección por ser "la única ciudad -valenciana- que vivió la primera revolución industrial" (Coput, 1991) en cita de Joan Lerma, Presidente de la Comunidad Valenciana entre 1982 y 1995, cuestión sin duda simbólica en el proceso de 
construcción del País Valencià. Por su parte, el Conseller de Obras Públicas, Urbanismo y Transportes, Eugenio Burriel, consideraba la operación de forma mucho "más integral", necesaria tanto para la recuperación del centro histórico, como de la propia ciudad de Alcoy y de las comarcas industriales del interior, afectadas por una fuerte crisis (CорUT, 1991). El Conseller apelaba al necesario giro desde los planteamientos conservacionistas - centrados en el aspecto arquitectónico- de los primeros planes sobre centros históricos valencianos (GAJA, 2001) hacia las "estrategias integrales" derivadas de las intervenciones en los centros históricos de Italia en los años 1970 -Bolonia y Brescia significativamente- que conjugaban también propuestas de recuperación social y funcional (FERNÁNDEZ, 1994).

Desde el lado técnico, el giro hacia la renovación desde los primeros planes conservacionistas halla justificación en la influencia de otra serie de arquitectos urbanistas muy vinculados con el Movimiento Moderno, las propuestas innovadoras y siempre renovadoras de los CIAM para los centros históricos y la urbanística contemporánea.

Destacado ha sido el papel de Manuel Vidal Vidal, arquitecto alcoyano redactor del primer Plan de Rehabilitación del Centro Histórico en 1984, que iniciaba los procesos de renovación del hábitat de carácter social con el grupo de viviendas de la Plaçeta Les Xiques en el Raval Vell (1987-1991). Colega de otros urbanistas modernos y neo-modernos, como Rafael Moneo, quien dirigió su tesis doctoral titulada Arquitectura e industria: un ensayo tipológico de los edificios fabriles de L'Alcoià, editada en 1988 por la COPUT. Presumiblemente, a partir de ese núcleo llegaron otros urbanistas renovadores, como Carlos Merí Cucar, redactor del Plan Especial de Reforma Interior para el Casco Antiguo de 1989, frontalmente rechazado por la ciudadanía por sus drásticas medidas renovadoras.

También el redactor del PGOU de 1989, José Antonio Torroja puede adscribirse claramente a esa tendencia renovadora. Más aún Manuel de Solà-Morales, teórico y formador de generaciones de urbanistas, autor de Teoría de la forma de la arquitectura en el Movimiento Moderno (1982), coautor con Rafael Moneo del diseño de L'Illa Diagonal (premio FAD, 1994) y con Manuel Vidal del Barri de La Sang (premio IBER-FAD 1999). Sóla-Morales, alumno directo de Josep Lluis Sert, se ha caracterizado tanto por su defensa del papel primordial del diseño del espacio público, como por su rechazo del urbanismo administrativo (el urbanismo sujeto a complejas tramitaciones y supervisiones, tal como los planes especiales), así como por dar prioridad a la recuperación de la función del barrio antes que la rehabilitación de los edificios, aspectos esenciales para entender la 
tramitación de todo el Plan ARA y, en concreto, el proyecto y concreción del Barri La Sang.

\section{III.3.a. La gestión pública integral de la renovación: mecanismos y herramientas legales y financieras}

En general, tanto ideológica como técnicamente, se aspiraba a gobernar desde las instancias públicas todo un proceso integral de planeamiento, gestión, urbanización y edificación directa, a base de proyectos de ejecución (de expropiaciones, demoliciones, urbanización y edificación), por encima, o al margen, de los complejos trámites administrativos inherentes a todo proceso urbanístico, máxime cuando el proyecto se centra en un espacio urbano consolidado que, además, está catalogado como Bien de Interés Cultural.

El ambicioso Plan ARA fue gestionado y financiado por la Generalitat Valenciana a través del IVVSA, con unos presupuestos que excedían con mucho la capacidad financiera del propio Ayuntamiento. De hecho, no es ni un plan especial de reforma interna, ni un plan especial de centro histórico, se trata sólo de una acumulación coordinada de proyectos de ejecución, posibles por la interpretación interesada de la normativa del PGOU de 1989 (Anexo 1. Ordenación de Casco Antiguo).

En ese proceso, en 1991 el centro de Alcoy (y otros barrios periféricos de la ciudad como Caramanchel y Batoy) fueron incluidos en el catálogo de Barrios Vulnerables de España (Ministerio de Fomento), lo que abría nuevas vías de financiación para la puesta en marcha de proyectos urbanos de recuperación. En esos momentos, el centro histórico alcanzaba tal proceso de abandono y degradación que el Ayuntamiento pudo hacerse con un importante patrimonio municipal de suelo simplemente por asumir los costes del derribo de los edificios declarados en ruina: con mucha frecuencia la expropiación "salía gratis", bien porque los herederos de los antiguos propietarios desconocieron el proceso o porque no le prestaron atención, ya que por lo general sólo eran propietarios de una minúscula fracción del solar resultante de la demolición, o no podían demostrar que lo eran.

Ese paquete de suelo público constituía la principal aportación del municipio al proceso, puesto al servicio del IVVSA para la construcción primero de nuevas viviendas y luego de grandes proyectos de infraestructuras y equipamientos. El PGOU de 1989 señalaba como instrumentos de ejecución los proyectos técnicos de urbanización, de edificación y de "otras obras" (art. 43). Por su parte, el Anexo 1. Ordenación de Casco Antiguo, en su artículo 5, indicaba que la ejecución del plan general podría llevarse a cabo directamente, "o bien a partir de los 
planes especiales y estudios de detalle que desarrollen o modifiquen -lo dispuesto en el PGOU- cuando las determinaciones del plan general no hubieran alcanzado el suficiente grado de pormenorización". De ese modo, vinculados con el PGOU podían desarrollarse proyectos y obras en el centro histórico, siempre que las propuestas de ejecución fuesen pormenorizadas e integrales, esto es, incorporando propuestas de reparcelación, expropiación o compensación, urbanización y edificación y no alterasen las grandes directrices del PGOU (el proyecto contra el plan).

La incertidumbre legal quedaba subsanada en 2002 (ya construido el $B a$ rri La Sang y las renovaciones de Buidaoli, del Raval Nou (Plaçeta les XiquesMuralla Barbacana y Portal de Riquer) se procedía a aprobar una "Homologación del Casco Antiguo delimitado por el PGOU" (redactada por los urbanistas de Alcoy José Abad Pérez y C. Gloria Domenech) y con ella se homologaban todos los proyectos de ejecución llevados a cabo con anterioridad. En 2003 se aprobaba un PERI del Casco Antiguo Sector-1 por los mismos arquitectos (para el recinto amurallado), en 2005 se tramitaba el PERI del Casco Antiguo Sector-2 para las actuaciones en La Riba, con mucha contestación ciudadana por las propuestas de renovación y en 2008 se tramitaba otro PERI para acomodar las instalaciones de la Universidad Politécnica en el centro histórico de la ciudad.

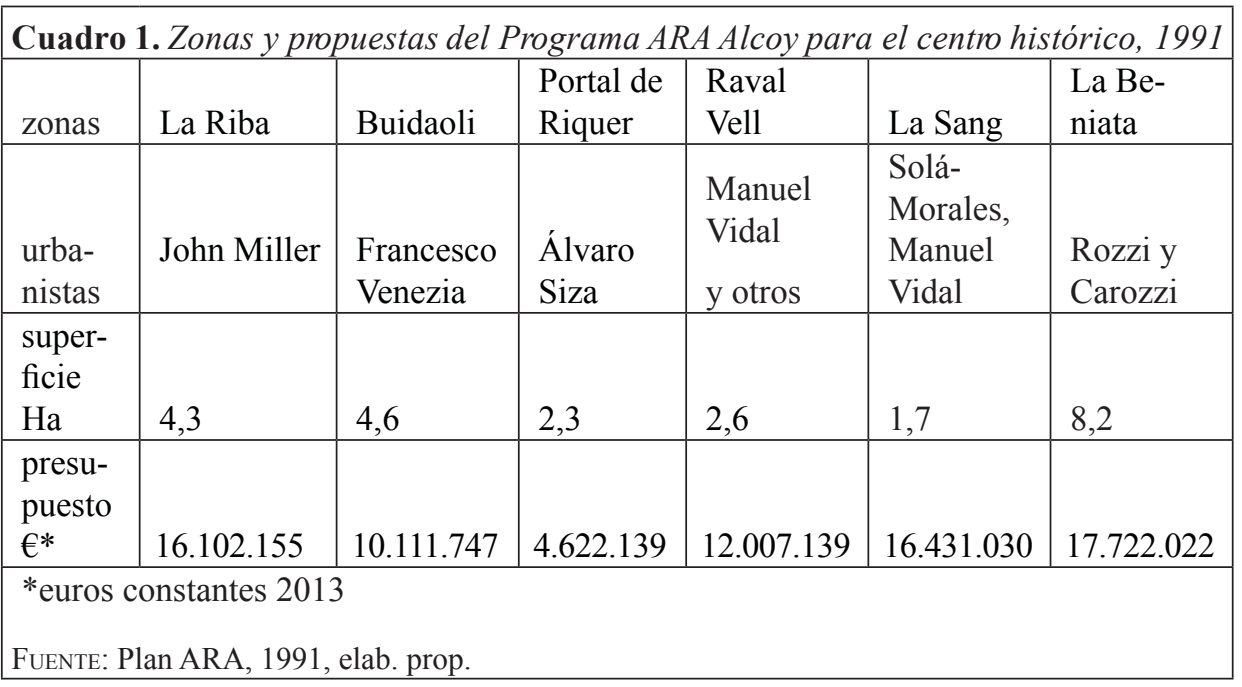

Por su parte, el IVVSA se convertía en la herramienta financiera esencial, que contrataba a los estudios de arquitectura y urbanismo para el desarrollo de viviendas y diversos equipamientos. Mientras otras infraestructuras, como las ga- 
lerías subterráneas de servicios o los parques, eran costeadas o bien directamente por la COPUT o bien por otros organismos públicos estatales. Sin contar esas inversiones en infraestructuras, las destinadas directamente a viviendas en las diferentes zonas del centro histórico ascendían a unos 77 millones de euros constantes, para aplicar sobre unas $24 \mathrm{Ha}$ del conjunto histórico-artístico convertidas previamente en solares púbicos edificables.

Como se verá, de esas propuestas tan solo se han concretado las del Raval Vell y La Sang, ambas con participación de Manuel Vidal -arquitecto local-. No obstante, en la última fase ya de impulso privado, el IVVSA ha seguido colaborando con ayudas económicas dentro de los planes estatales de acceso a la vivienda (Ministerio de Fomento), concretado en el Programa Restauro de la Comunidad Valenciana y en el Plan de acceso a vivienda 20042007.

Cuadro 2. Programa Restauro Comunidad Valenciana. Plan acceso a vivienda 20042007.

Ayudas en el centro histórico de Alcoy

\begin{tabular}{|l|l|l|l|}
\hline & \multicolumn{3}{|c|}{ viviendas } \\
\hline zona & rehabilitación & VPO & VPT \\
\hline La Vila & 5 & 6 & 4 \\
\hline Raval Vell & 7 & 0 & 2 \\
\hline Centro Plaza España & 18 & 0 & 1 \\
\hline Raval Nou & 61 & 9 & 1 \\
\hline San Nicolás & 37 & 0 & 0 \\
\hline Sant Nicolauet & 31 & 5 & 10 \\
\hline $\begin{array}{l}\text { Santa Elena } \\
\text { (primer ensanche) }\end{array}$ & 34 & 5 & 10 \\
\hline C/ Casa Blanca borde Molinar & 6 & 0 & 6 \\
\hline Total & 199 & 25 & 34 \\
\hline FuenTE: IVVSA, elab. prop. & & & \\
\hline
\end{tabular}

Además, los objetivos del Plan ARA se han beneficiado del Plan de Urbanismo Comercial que antecedía en unos años las propuestas de los Planes de Acción Comercial (PACs), iniciados en 1998 por la Generalitat Valenciana y concretado en el PAC de Alcoy en 2001-2002, como instrumento para dinamizar la ciudad en su conjunto (y también en el centro histórico) a través del comercio, mediante estrategias integrales (sociales, inmobiliarias y urbanísticas) que coincidían con los objetivos específicos del Plan ARA y, por ello, sumaban sinergias. 
III.3.b. El cambio de paradigma: la iniciativa privada como motor de los procesos

\begin{tabular}{|c|c|c|c|c|c|c|c|}
\hline \multicolumn{8}{|c|}{ Cuadro 3. Cambios politicos y afecciones al Plan ARA } \\
\hline \multirow[b]{2}{*}{$\begin{array}{l}\text { man- } \\
\text { dato }\end{array}$} & \multicolumn{2}{|c|}{$\begin{array}{l}\text { Alcaldía de } \\
\text { Alcoy }\end{array}$} & \multicolumn{3}{|c|}{ Gobierno Valenciano } & \multirow{2}{*}{\multicolumn{2}{|c|}{ Paradigmas y criterios }} \\
\hline & $\begin{array}{l}\text { alcal- } \\
\text { de }\end{array}$ & $\begin{array}{l}\text { parti- } \\
\text { do }\end{array}$ & $\begin{array}{l}\text { man- } \\
\text { dato }\end{array}$ & $\begin{array}{l}\text { presi- } \\
\text { dente }\end{array}$ & $\begin{array}{l}\text { parti- } \\
\text { do }\end{array}$ & & \\
\hline & & & $\begin{array}{l}1978- \\
1979\end{array}$ & $\begin{array}{l}\text { J. Ll. } \\
\text { Albi- } \\
\text { ñana }\end{array}$ & PSOE & \multicolumn{2}{|c|}{ Normas Complementarias } \\
\hline $\begin{array}{l}1979- \\
1983\end{array}$ & $\begin{array}{l}\text { J. } \\
\text { Sanus }\end{array}$ & PSOE & $\begin{array}{l}1979- \\
1982\end{array}$ & $\begin{array}{l}\text { E. } \\
\text { Mon- } \\
\text { sonís }\end{array}$ & UCD & \multicolumn{2}{|c|}{ Normas Subsidiarias } \\
\hline $\begin{array}{l}1983- \\
1987\end{array}$ & $\begin{array}{l}\text { J. } \\
\text { Sanus }\end{array}$ & PSOE & $\begin{array}{l}1982- \\
1995\end{array}$ & $\begin{array}{l}\text { J. Ler- } \\
\text { ma }\end{array}$ & PSOE & PRCH & $\begin{array}{l}\text { conservadu- } \\
\text { rismo }\end{array}$ \\
\hline \multirow[b]{2}{*}{$\begin{array}{l}1987- \\
1991\end{array}$} & \multirow[b]{2}{*}{$\begin{array}{l}\text { J. } \\
\text { Sanus }\end{array}$} & \multirow[b]{2}{*}{ PSOE } & \multirow[b]{2}{*}{$\begin{array}{l}1982- \\
1995\end{array}$} & \multirow[b]{2}{*}{$\begin{array}{l}\text { J. Ler- } \\
\text { ma }\end{array}$} & \multirow[b]{2}{*}{ PSOE } & \multirow{2}{*}{$\begin{array}{l}\text { Plan ARA } \\
\text { suelo público } \\
\text { gestión pú- } \\
\text { blica integral }\end{array}$} & renovación \\
\hline & & & & & & & \\
\hline $\begin{array}{l}1991- \\
1995\end{array}$ & $\begin{array}{l}\text { J. } \\
\text { Sanus }\end{array}$ & PSOE & $\begin{array}{l}1982- \\
1995\end{array}$ & $\begin{array}{l}\text { J. Ler- } \\
\text { ma }\end{array}$ & PSOE & $\begin{array}{l}\text { Barri La } \\
\text { Sang }\end{array}$ & $\begin{array}{l}\text { Corazón de } \\
\text { la Ciudad }\end{array}$ \\
\hline $\begin{array}{l}1995- \\
1999\end{array}$ & $\begin{array}{l}\text { J. } \\
\text { Sanus }\end{array}$ & PSOE & $\begin{array}{l}1995- \\
2002\end{array}$ & $\begin{array}{l}\text { E. Za- } \\
\text { plana }\end{array}$ & PP & crisis $\boldsymbol{A R A}$ & $\begin{array}{l}\text { replantea- } \\
\text { miento }\end{array}$ \\
\hline $\begin{array}{l}1999- \\
2000\end{array}$ & $\begin{array}{l}\text { J. } \\
\text { Sanus } \\
\end{array}$ & PSOE & $\begin{array}{l}1995- \\
2002 \\
\end{array}$ & $\begin{array}{l}\text { E. Za- } \\
\text { plana }\end{array}$ & PP & paralización & $\begin{array}{l}\text { de ilusión a } \\
\text { carga }\end{array}$ \\
\hline $\begin{array}{l}2000- \\
2003\end{array}$ & $\begin{array}{l}\text { M. } \\
\text { Peral- } \\
\text { ta }\end{array}$ & $\mathrm{PP}$ & $\begin{array}{l}2002- \\
2003\end{array}$ & $\begin{array}{l}\text { J. L. } \\
\text { Olivas }\end{array}$ & PP & Paisajismo & $\begin{array}{l}\text { Postmoder- } \\
\text { nidad }\end{array}$ \\
\hline $\begin{array}{l}2003- \\
2007 \\
\end{array}$ & $\begin{array}{l}\text { J. Se- } \\
\text { dano }\end{array}$ & $\mathrm{PP}$ & $\begin{array}{l}2003- \\
2011 \\
\end{array}$ & $\begin{array}{l}\text { F. } \\
\text { Camps }\end{array}$ & PP & $\begin{array}{l}\text { promoción } \\
\text { privada }\end{array}$ & $\begin{array}{l}\text { Neolibera- } \\
\text { lismo }\end{array}$ \\
\hline $\begin{array}{l}2007- \\
2011 \\
\end{array}$ & $\begin{array}{l}\text { J. Se- } \\
\text { dano }\end{array}$ & PP & $\begin{array}{l}2003- \\
2011 \\
\end{array}$ & $\begin{array}{l}\text { F. } \\
\text { Camps }\end{array}$ & PP & $\begin{array}{l}\text { venta de } \\
\text { suelo }\end{array}$ & $\begin{array}{l}\text { negocio in- } \\
\text { mobiliario }\end{array}$ \\
\hline
\end{tabular}

En 1995 se alteraba sustancialmente el equilibrio político: mientras el alcalde del PSPV-PSOE inauguraba su cuarto mandato consecutivo, el Partido Popular conseguía la presidencia del Gobierno valenciano. Se interrumpía la fluidez entre Ayuntamiento y el IVVSA, y el Programa ARA entraba en crisis. Si desde 
el Ayuntamiento se mantenían las esperanzas de concluir todos los proyectos presentados, desde el Gobierno de la Generalitat se procedía a un profundo replanteamiento de las actuaciones pendientes y, sobre todo, se cuestionaba el criterio de la gestión pública integral. El colapso total se dio en el año 2000, cuando el alcalde del PSPV cedió la alcaldía mediante diversos pactos al Partido Popular.

El freno al Plan ARA no puede achacarse a la falta de recursos, como evidencia la etapa de excesos urbanísticos y la acumulación de macro proyectos en territorio valenciano que tendría lugar en el decenio siguiente. Más bien obedece a un evidente cambio de paradigma general, que puede sintetizarse en los siguientes aspectos:

- con el asentamiento del neoliberalismo como paradigma económico, desde el Ayuntamiento se abandonaba paulatinamente la idea de gestión pública integral y se daba entrada a la iniciativa privada en las tareas de reconstruir el demolido centro histórico;

- la progresiva dilución y olvido de las "estrategias de vertebración territorial" diseñadas para la Comunidad Valenciana por los gobiernos previos de signo progresista, recogidos en el Plan de Acción Territorial Integrado de Desarrollo Urbanístico de 1995 (BURRIEL, 2009); con ello se abandonaba el incipiente proceso de comarcalización y de creación de nuevas capitalidades funcionales de diferentes rango - caso de Alcoy-, y se volvía al reforzamiento de las capitales provinciales;

- afectada esa capitalidad, el centro histórico ya no debía convertirse en un nuevo centro cívico, comercial y de negocios (recuperar sus funciones de centralidad), bastaba con recuperar su función residencial;

- de ese modo las innovadoras y regeneradoras (y criticadas popularmente) propuestas de los grandes gabinetes de urbanismo eran desdeñadas y sustituidas por rutinarios procesos de construcción de nuevos bloques de viviendas con fachadas historicistas (acumulación de balcones), no tipológicas, que buscan efectos paisajísticos.

La redacción de la Homologación del Casco Antiguo delimitado por el $P G O U$, de 2002, ya con gobiernos neoliberales en el Ayuntamiento y en la Generalitat, introducía el cambio en el modelo de gestión. A partir de ese momento, la iniciativa privada aprovechaba la nueva orientación y procedía a comprar el suelo vacante en el centro histórico y a sustituir la iniciativa pública en la promoción de viviendas, en operación tildada de especulativa por el PSPV-PSOE local, al señalar que el Ayuntamiento perdía el control del proceso de reconstrucción del centro histórico y que éste quedaba en manos de los intereses concretos de la empresa privada, supeditada evidentemente a ritmos de promoción marcados, no 
por las necesidades de Alcoy, sino por las de un mercado desbocado que miraba más a la costa que al interior (diario Información, 27/06/2003) y que olvidaba el criterio social de la promoción de viviendas.

Desde el Ayuntamiento se ha procedido a la venta del suelo público acumulado en la etapa anterior, lo que ha suscitado no pocas críticas por cuanto muchas de las adquisiciones se hicieron por expropiación forzosa -mediante declaraciones de ruina- empujando a los antiguos vecinos a abandonar sus viviendas (bien en propiedad, bien en alquiler) desplazados no siempre de buen grado hacia otras barrios. Al tiempo, muchos de los antiguos propietarios que no reclamaron su propiedad por considerar que el proceso de renovación pública perseguía notables objetivos sociales, o que aceptaron exiguas compensaciones, critican que ahora la iniciativa privada se lucre de sus antiguas propiedades.

\section{III.4 Síntesis de las propuestas del Programa de Revitalización Urbana de Alcoy}

Como va dicho, se trata de un programa de actuaciones y no de un plan concreto, centrados en la recuperación socioeconómica de Alcoy. Sus objetivos pueden sintetizarse en los siguientes:

- la configuración de una potente ciudad terciaria para capitalizar las comarcas centrales de la Comunidad Valenciana (entre Valencia y Alicante)

- la animación de las iniciativas locales, tras el fuerte impacto de la crisis industrial en el subsector del textil, para seguir dando servicios cualificados a la industria, sobre la base de la investigación y el diseño y la promoción del denominado sector servindustrial;

- la cualificación de la escena urbana y la mejora de la calidad de vida de una ciudad decadente y en crisis, para consolidar la población tanto en el centro histórico, como en el conjunto del municipio (que perdía habitantes, empresas e inversiones).

Para ello se articularon varios programas (denominados oficialmente planes, cuando en realidad se trataba de líneas estratégicas de actuación), concretados en:

- el Programa de Revitalización Urbana de Alcoy, que contenía el denominado Plan ARA para el centro histórico, el programa de parques periféricos y el programa de "otras obras" básicamente de equipamientos e infraestructuras;

- el Programa formativo para la cualificación de la mano de obra en el manejo de nuevas tecnologías orientadas hacia la reconversión industrial y, también, para el fomento de nuevas actividades terciarias cualificadas (entre otras medidas, a 
este programa responde la instalación de un campus dependiente de la Universidad Politécnica de Valencia y los estudios de ciclo superior de la Formación Profesional).

\section{III.4.a. Marco teórico de las propuestas: la innovación urbanística} como motor del cambio

Se ha indicado la influencia de los planes italianos, al menos en lo referente a su carácter integral, atendiendo al tiempo a los aspectos sociales y funcionales, junto con la conservación de los edificios catalogados. Más aún, esa influencia queda patente en la asunción de un fuerte liderazgo público. Sin embargo, a partir de ahí, comienzan las diferencias que orientaron los criterios de intervención en Alcoy, tales como la imposición del criterio técnico a la opinión ciudadana, o la renovación de la escena frente a la rehabilitación, que acercan las propuestas al marco teórico del Movimiento Moderno (con toda su complejidad y matices en su largo discurso cronológico).

En concreto, respecto del Plan ARA, la hipótesis central sostiene que la recualificación y el cuidado diseño de los espacios públicos centrales actúan como motor de la regeneración, al atraer inversiones privadas. Así, la herramienta fundamental para conseguirlo es el esponjamiento de las fuertes densidades del viejo callejero, la reurbanización del mismo, prestando a una minuciosa atención al diseño de los espacios públicos (en línea con Solà-Morales, Josep Lluis Sert y el Corazón de la Ciudad) y la construcción de nuevas viviendas acordes con las exigencias del hábitat contemporáneo.

Del análisis de las intervenciones habidas y de los proyectos no concretados se evidencia la fuerte componente innovadora ante el reto de la recuperación del centro histórico de Alcoy. Si las medidas oficiales previas tendían a priorizar la conservación pasiva de la obra construida (el ladrillo en expresión actual) frente a la conservación activa de la vida y las funciones, expulsadas por la pérdida de funcionalidad de las viejas viviendas y las estrechas calles, las propuestas urbanísticas del Plan ARA alteraban las prioridades, poniendo el foco de atención en la recuperación de la vida y las funciones. Para ello, debía renovarse completamente el centro histórico, siguiendo los criterios del pensamiento moderno, recogidos en los sucesivos Congresos Internacionales de Arquitectura Moderna (CIAM). Se exponen a continuación las principales directrices de esos congresos que han sido identificadas en las propuestas del Plan ARA de Alcoy.

El primer CIAM, en 1928, en el que se criticaba el mantenimiento de los criterios historicistas para la reconstrucción de la Europa afectada por la I Guerra Mundial, acababa con un manifiesto para que la arquitectura contemporánea se 
impusiera a la arquitectura "oficial historicista" para los centros históricos. Se indicaba la necesidad de urbanizar -reurbanizar los centros históricos- conforme con criterios funcionales y mediante un diseño colectivo, y se proponía la construcción de viviendas estandarizadas y racionalizadas (ajustadas a las necesidades de la vida contemporánea) como la mejor solución para recuperar el atractivo de los espacios históricos de la ciudad.

El segundo CIAM, en 1929, tuvo por tema central el diseño de viviendas de interés social, que debían ser tan dignas como las demás, contener todos los estándares de espacios para usos domésticos, contar con un mobiliario mínimo integral para cocinas, armarios y camas (como en el Barri La Sang) y resultar eficientes y de bajo mantenimiento a partir de un diseño muy cuidado.

En el tercer CIAM, en 1930, se discutía sobre el desarrollo de un método racional para planear "el sitio" o emplazamiento en que debía ejecutarse el proyecto. Este es aspecto esencial de todas las propuestas urbanísticas del Plan ARA, tanto por los propios criterios científicos, como por los retos que la quebrada topografía del centro histórico de Alcoy proponía a los urbanistas. Se proponía la segregación de sendas peatonales y vías rodadas (La Sang y Plaçeta Les Xiques), y la mejor ubicación y diseño de los bloques de viviendas respecto de las condiciones de la Naturaleza (exposición al Sol, aireación, vistas y recreación de espacios verdes), identificando los bloques de viviendas en hilera, siempre bien orientados, como la solución ideal (Barri La Sang).

En el cuarto CIAM, en 1933, se definía el principio de zonificación, o separación de los usos funcionales de la ciudad, por considerarse incompatibles. Es el principio que inspira el planeamiento urbanístico estatal, desde 1956 (con la primera Ley del Suelo) hasta la actualidad. Todos los planes generales han mantenido, hasta hace unos años, la segregación de los espacios funcionales como auténtico dogma de fe, más que como paradigma científico (sujeto a revisión y crítica). Así, todas las figuras de planeamiento habidas en Alcoy hasta el presente se han guiado por esa idea central de la segregación de las funciones, concretadas en la expulsión de la actividad industrial hacia las periferias y la prohibición, en Alcoy, de la actividad industrial en su primigenio asentamiento, en el fondo de los barrancos, junto a la corriente de agua que generó su primera fuerza motriz (dejar "fuera de ordenación" esos espacios industriales fue su sentencia de muerte, agravó la crisis del textil y desencadenó la ruina física que todavía ofrece sin solución aparente al menos el Río Molinar, mientras el otro río industrial de la ciudad, el Barxell, experimentó una fuerte transformación con motivo de la canalización y ajardinamiento de su curso a su paso por la ciudad, por los planes “anti-riadas"). 
Más allá de esos aspectos generales, para el caso de estudio interesan las propuestas que se hacían para las cuatro funciones urbanas identificadas:

- Habitar: en un sólo tipo de vivienda urbana, en bloque abierto (se exige el retranqueo respecto de la calle para recrear espacios verdes y alejarse del ruido), con el máximo de luz y sol posibles; se trata de las propuestas que recogía el rechazado PERI para el Casco Antiguo de 1989 y el ejecutado proyecto del Barri La Sang.

- Trabajar: en espacios industriales alejados de la ciudad (polígonos periféricos) y en un espacio comercial y de negocios (centro terciario) también segregado del hábitat.

- Cultivar el cuerpo y el espíritu: con el objetivo principal de que "los ríos, colinas y valles... se integren en la ciudad", para ello era preciso abrir el cerrado callejero a su entorno natural, demoliendo manzanas insalubres que debían ser convertidas en zonas verdes (esponjamientos urbanos) y diseñar los barrios con espacios verdes y áreas de juego (La Sang).

- Circular: la separación de usos obligaba a trazar vías eficientes de comunicación entre ellos, que también debían diseñarse para acoger específicamente un tipo de flujo: rodado -rápido o lento- y peatonal. En La Sang se evidencian también estos conceptos: diseño de las calles según su función (rodada, peatonal, de acceso a los aparcamientos subterráneos) todas a diferente nivel sin encrucijadas; los ejes están perfectamente diseñados conforme con su clasificación jerárquica: calles habitacionales, calles de paseo, calles de tránsito, calles comerciales. Por último, el barrio o polígono residencial debía estar bien comunicado con las vías de circulación rápida, para favorecer el acceso a los polígonos periféricos, aspecto más condicionado en un centro histórico como el de Alcoy, aunque La Sang se levanta junto a la antigua carretera nacional a su paso por el casco urbano (El Cami).

Más concluyentes son las influencias del IV CIAM en Alcoy respecto del tratamiento del patrimonio. Se mantenía la necesidad de un catálogo de edificios de alto valor patrimonial, pero también se señalaba que su protección quedaba condicionada a que no afectasen a la vida contemporánea de la zona. En general, aspirando a la mejora de las condiciones de vida de los obreros, se proponía demoler "los tugurios" y convertirlos en zonas verdes.

En el V CIAM, en 1937, se analizaba el impacto de las estructuras urbanas históricas en la organización de la región circundante. Se proponía la ciudad como elemento fundamental en la ordenación del territorio regional; esto es, se daba un salto cualitativo desde la ordenación urbana (planeamiento urbano) hacia la ordenación territorial (planeamiento supramunicipal) subordinada a la ciudad. 
Se trata de aspecto esencial en el Programa de Revitalización Urbana de Alcoy (matriz que incluye el Plan ARA), tal como se ya ha señalado.

Es en el VIII CIAM, en 1951, cuando aparecen las ideas esenciales aplicadas en el Plan ARA. Se trata del desarrollo del concepto de Corazón de la ciudad definido por Josep Lluis Sert. Para Sert, la única ventaja real de vivir en una ciudad era la de acercar a las personas entre sí y favorecer el intercambio directo de conocimiento e información: "que la gente intercambie ideas y sea capaz de discutirlas de forma libre" ya que en los barrios periféricos "las noticias o información o visiones o imágenes" llegan siempre a través de medios de comunicación intervenidos por diversos intereses: "uno ve solo lo que se le muestra y escucha lo que se le es dicho... lo que resulta terriblemente peligroso" (SERT, 1955). Por ello, ante el proceso de dispersión propiciado por el propio Movimiento Moderno y la zonificación, era necesaria la recentralización de las áreas urbanas alrededor de centros peatonales con capacidad para atraer y reunir a la gente. Así, debía recuperarse el antiguo centro social de la ciudad, pero renovado conforme a los criterios de funcionalidad y a las exigencias de la vida contemporánea. Por ello, debían ser peatonales y ajardinados, pero muy accesibles para el tráfico rodado, que debía contar con los suficientes aparcamientos en el centro para que éste resultase eficiente y atractivo. Se trata, sin duda, de la idea central del Plan ARA, acomodada por los diferentes equipos de urbanistas en sus proyectos: esponjamiento y creación de zonas verdes, grandes aparcamientos, nuevas construcciones que permitiesen el acogimiento eficaz de los nuevos usos comerciales y terciarios.

En el IX CIAM se debatía otra cuestión trascendental para el diseño de los espacios residenciales del Plan ARA: la extensión de la vivienda fuera de sus propios muros. Es idea que enraíza claramente con la vieja tradición mediterránea de extender los usos del hábitat doméstico en la propia calle (que se barría, regaba y llenaba de plantas en macetas para hacer más acogedoras las tertulias con los vecinos: la calle tradicional como espacio del encuentro y la relación frente a la calle contemporánea para el tránsito rápido). Por consiguiente, el barrio debía ser diseñado para que sus calles y espacios abiertos favoreciesen la relación entre vecinos y familias, como en La Sang, con el objetivo de recuperar la relación social directa (muy afectada en las urbanizaciones periféricas). Objetivo específico, explícitamente perseguido en La Sang, era el de lograr identificar al vecino con su barrio: el barrio debía ser la unidad habitacional mínima, y no la vivienda (que evolucionaba hacia nicho de aislamiento).

Por último, en el X CIAM, en 1956, se insistía en que la arquitectura contemporánea era la herramienta fundamental para resolver el problema moral de 
la infravivienda. Tales eran las doctrinas urbanísticas más innovadoras en los años 1960, cuando se forjaron como arquitectos los principales técnicos que han intervenido en el Plan ARA.

\section{III.5 Análisis de las propuestas en su evolución}

El Plan Arquitectura y Rehabilitación de Alcoy -Plan ARA- contemplaba cinco zonas de actuación en el centro histórico: La Riba, Buidaoli, Portal de Riquer, La Beniata y La Sang; para "la conjunción de trabajos de demolición selectiva, rehabilitación y construcción de nuevas edificaciones, con un tratamiento de renovación y consolidación de la infraestructura... reforzando el tejido urbano con una adecuación para su uso, en niveles de calidad, que refuercen la proyección de Alcoy como una ciudad singular dentro del contexto nacional" (CoPUT, 1991). Aunque se efectuó la primera fase -la demolición-, tan sólo uno de los cinco proyectos llegó a concretarse en su totalidad -La Sang-, mientras los otros cuatro o han sido definitivamente olvidados o han experimentado fuertes alteraciones desde su concepción original. Para nominarlos se ha utilizado el eslogan empleado el propio Plan ARA.

\section{III.5.a. Buidaoli. Sobre los cimientos de la Historia}

Figuras 1 y 2. Alcoy, planos de localización del Plan ARA y de las actuaciones previstas

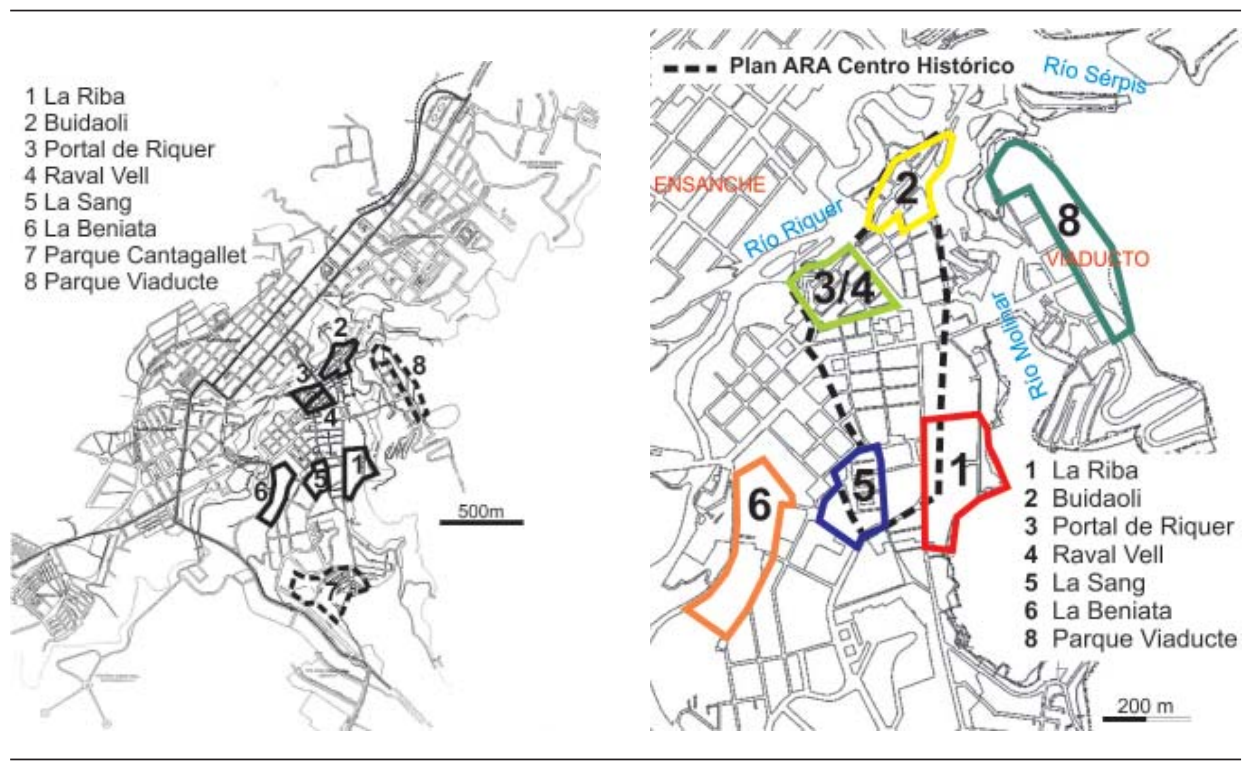

FuENTE: Plan ARA, COPUT, 1991, elab. prop. 
La zona de Buidaloli constituye el núcleo genético de la ciudad, fundado a partir de un asentamiento cristiano en forma de pequeña bastida. A partir de él se desarrollaron los arrabales Viejo y Nuevo (Raval Vell y Raval Nou), por eso, el espacio fundacional se denominó La Vila. Cuando se presentó el Plan ARA, ya se había acometido la construcción del primer grupo de viviendas sociales (19871991) a costa de la renovación completa de una manzana situada justo encima de la muralla. Se definió una zona de actuación de 4,6Ha, con un anteproyecto de unos 10 millones de euros (constantes) elaborado por el arquitecto Franzesco Venezia, que en Italia trabaja en la recuperación de ciudades afectadas por terremotos (con efectos similares a los derribos de Alcoy) y en la rehabilitación de viejos espacios industriales en frentes fluviales y marítimos.

Su propuesta se centraba en construir una gran plaza central al nivel del suelo en La Vila, y desde ella hacia abajo, aprovechando el desnivel del barranco del Río Barxell, un edificio de aparcamientos de 8 plantas. Pieza esencial para la recuperación del corazón de la ciudad histórica, bien que a costa de la demolición de toda La Vila, salvo los edificios catalogados (iglesias, algunos palacetes y las murallas sacadas a la luz con los derribos), en plena sintonía con las directrices de los CIAM.

Se derribó el viejo barrio, se liberaron las murallas pero no hubo más, hasta que a partir de 2002, la iniciativa privada pudo comenzar a intervenir libremente. En efecto, la aprobación en ese año de la Homologación de toda el área del Casco Antiguo iba acompañada de un Plan de Reforma Interior del Casco Antiguo, Sector 1, al que denominaban entre paréntesis Plan Especial de Protección para su aprobación en 2003 (BOP Alicante, 30/04/2003, no 98). Con ese apaño legal, se daba cauce a dos unidades de ejecución: la UE-1 para el Raval Vell y la UE-2 para Buidaoli-La Vila, con el objetivo explícito de "posibilitar la reutilización del área, rescatándola de la situación de abandono y degradación que la afecta".

La UE-2 se desarrollaba mediante simples cédulas de urbanización ejecutadas por la empresa La Retjola S.L., que construía cinco bloques de viviendas en la zona, en torno a las calles Sant Miquel, Sant Blai, Sant Antoni y Santo Tomás, de 4, 5 y 6 alturas conforme con las visuales del centro histórico, con bajos comerciales y aparcamientos subterráneos. Ubicados estratégicamente junto a la arteria viaria de Santo Tomás (que une las dos zonas terciarias de la ciudad a uno y otro lado del Puente Sant Jordi) y convenientemente alejada del primer grupo de viviendas sociales de Torre de Fraga (también en La Vila-Buidaoli), separada por extensos solares sin ocupar. Se trata ahora de viviendas de renta libre, con pisos de hasta $220 \mathrm{~m}^{2}$, que en 2012 tenían un precio medio de $950 € / \mathrm{m}^{2}$ construido, para una demanda de mayor nivel que las precedentes. 
La nueva promoción de viviendas, entregadas entre 2008 y 2009, alteraba completamente la propuesta inicial de una gran plaza pública y volvían a generar las altas densidades que se pretendía evitar.

\section{III.5.b. Portal de Riquer. Resaltar el patrimonio cultural para la vida cotidiana}

Portal de Riquer se halla sobre el lienzo de muralla que envuelve el Raval Vell. De hecho constituye un pequeño arrabal creado a partir de una puerta de la muralla. También aquí se había intervenido con anterioridad a la propuesta del Plan ARA (Plaçeta Les Xiques, Muralla-Barbacana, entre 1987 y 1991) para construir otro grupo de viviendas sociales. El espacio definido fue de 2,4Ha con un presupuesto de 4,6 millones de euros (constantes) sobre el que debía intervenir el estudio de Alvaro Siza que, en esencia, proponía "actuar con voluntad conservacionista y derribar únicamente lo ruinoso". Se derribó todo lo que enmascaraba la muralla, incluido el pequeño arrabal de San Roque, se escalonó y ajardinó el terraplén del Río Barxell.

La evolución posterior de la zona, merced a la aprobación en 2002 del Plan de Reforma Interior del Casco Antiguo, Sector 1 (Plan Especial de Protección), se ha concretado en el derribo integral de todo el Raval Vell, la rectificación del viario y la construcción de nuevos bloques de viviendas entre 2005 y 2010, con un 50\% de promoción privada y renta libre (conforme con los nuevos criterios de gestión), que se vendían en 2012 a una media de $1.200 € / \mathrm{m}^{2}$ construido. Para ello, el Ayuntamiento aprobó un Programa de Actuación Integrada (PAI) y delegó su gestión (gestión indirecta) en la empresa Juananser S.L. para su desarrollo mediante la UE-1, desde las expropiaciones hasta la construcción de las viviendas, pasando por la nueva urbanización del espacio histórico.

Los propietarios afectados alegaron su disconformidad con la gestión indirecta (mediante terceros con intereses empresariales) y con el proceso de expropiación "casi forzada" derivada de no poder participar mediante el sistema de cooperación en el desarrollo de la urbanización, por no poder hacer frente a sus costes. También consideraban improcedente la actuación mediante un Programa de Actuación Integrada (PAI), más propio para el desarrollo de suelo urbanizable que de suelo urbano consolidado. Pero el Ayuntamiento respondía que se trataba de un área infradotada y deficiente en todo tipo de equipamientos y que, por consiguiente, podía actuarse mediante un PAI para la renovación completa, como si efectivamente se tratase de un solar de la periferia.

Como en el caso de Buidaoli-La Riva, se procedía a renovar el centro histórico, pero con un producto más convencional y menos innovador que el de las 
iniciativas recogidas en el Plan ARA. De hecho, se procura ahora hacer negocio con la promoción de viviendas y, para ello, cuenta todo metro cuadrado en solares con tanta renta de situación. Si el Plan ARA esponjaba e introducía equipamientos y zonas verdes, la Homologación de 2002 simplemente sustituye viejas casas por otras nuevas.

\section{III.5.c. La Riba. Donde la ciudad mira al Río Molinar}

La Riba es una apretada zona ribereña que queda entre el Río Molinar y el eje urbano de San Nicolás. Se definió con una extensión de 4,3Ha y un presupuesto de anteproyecto de 16 millones de euros (constantes) elaborado por la oficina inglesa de Colquhoum, Miller + Partners Architects, autores del Proyecto para el Desarrollo de Milton Keynes (1975), una de las más simbólicas new towns impulsadas por el Movimiento Moderno y los CIAM. Se proponía la construcción de bloques de viviendas y palacetes unifamiliares sobre el borde ajardinado del río.

Olvidado el proyecto, pero acuciantes las necesidades de viviendas en la zona (afectada por numerosos expedientes de ruina), en 2008 se anunciaba el convenio entre el Ayuntamiento y el IVVSA "para la actuación en área de Suelo Urbano". En efecto, se consignaba cómo el Plan de Reforma Interior Sector II (Raval Nou, Sant Nicolau) no se había aprobado (todavía hoy no lo está). La Ley 16/2005 Urbanística Valenciana faculta a los organismos públicos valencianos con competencias a promover programas, planes parciales, planes de reforma interior, estudios de detalle y proyectos de urbanización, que se tramitarán conforme a las reglas propias de los planes especiales (artículo 89). De ese modo, otro nuevo apaño legal permitía la redacción de un Plan Especial de Vinculación a Vivienda Protegida para el área de La Riba.

El objetivo esencial era urbanizar la zona por el IVVSA y "ofrecer los solares urbanizados a precio tasado, destinado fundamentalmente a la construcción de viviendas sujetas a algún régimen de protección pública" (BOP Alicante, 28/10/2008, $\mathrm{n}^{\circ}$ 207) algunas de las cuales serían construidas por el propio IVVSA y las demás por la iniciativa privada. El conseller de Urbanismo anunciaba en ese año que se daría prioridad para el acceso a la vivienda a los jóvenes de hasta 35 años y a las familias que buscasen su primera vivienda. También indicaba que, "gracias a la colaboración entre Gobierno valenciano y Ayuntamiento de Alcoy, éste se beneficiaría del Plan Estratégico de Vivienda del Consell, concebido como una herramienta rápida y eficaz para aumentar la oferta de vivienda protegida en los próximos años en esta población". Cinco años después, tan sólo se ha realizado el obligado proceso 
participativo para la integración paisajística, tal vez para calmar a la combativa Asociación de Vecinos y Vecinas de El Partidor (junto a La Riba), la zona más afectada por la ruina y los derribos y presumiblemente beneficiaria de esas nuevas viviendas.

\section{III.5.d. La Beniata. Una puerta de entrada con paisaje}

De todas las propuestas, es la que menos desarrollo ha tenido. Se trataba de acondicionar paisajísticamente la entrada en la ciudad de la carretera N-340, que discurre por el borde del centro histórico, actuando básicamente sobre desmontes, terraplenes y jardines privados, por ello, no hubo derribos ni expropiaciones. No obstante la apertura en 1989 del puente atirantado de Fernando Reig, financiado por el MOPU, alteró sustancialmente los flujos de tránsito y la zona de actuación de La Beniata quedó relegada a una posición marginal. El anteproyecto fue redactado por el equipo encabezado por los italianos Renato Rozzi y Carlo Carozzi, autores de diversos planes de ordenación urbana y de centros históricos en Italia. La superficie acotada era de $8,2 \mathrm{Ha}$ y la estimación inicial de gasto de unos 18 millones de euros (constantes).

En la zona, la instalación del campus de la Universidad Politécnica de Valencia que, desde 2006, aprovechando varios edificios fabriles en desuso, y mediante el Plan Especial de Delimitación para reserva de suelo dotacional, de 2008 , se ha construido un aparcamiento en superficie para dar servicio al equipamiento docente como única concreción.

\section{III.6 El Barri La Sang como paradigma del proceso}

En diferentes apartados de este análisis se ha citado el Barri de la Sang como ejemplo de la concreción de las teorías y métodos de gestión. De hecho es el único caso de proyecto concretado dentro del Plan ARA con los mismos criterios con los que se diseñó en origen. El antiguo barrio obrero se alzaba en el borde sur del centro histórico, apoyado en el Camino de Alicante ( $E l$ Cami), con los mismos procesos de despoblación y abandono que aquejan a otros barrios de la zona, como El Partidor y el Forn del Vidre que quedaron fuera del límite acotado por el Plan ARA y hoy se hallan muy afectados por la ruina.

El proyecto se concibió como una unidad de ejecución integral, al margen del PGOU, que contemplaba demolición, reparcelación, urbanización y construcción de viviendas y equipamientos sobre un solar que ocupa $1,7 \mathrm{Ha}$ de las que realmente llegó a ocupar tan sólo $1 \mathrm{Ha}$, ya que el frente de la Glorieta no se 
ejecutó inicialmente (luego se colmató de edificios historicistas). Contaba con un presupuesto inicial de unos 16 millones de euros (constantes), aportados por el IVVSA (el Ayuntamiento aportaba el suelo), si bien en 2006, ante las quejas de los vecinos, desde el Gobierno valenciano se indicaba que la ejecución completa había tenido un sobrecoste del $20 \%$, a partir de las cuentas de la Sindicatura, lo que supondría unos costes reales próximos a los 20 millones de euros constantes (Sindicatura, 2001-2006).

El nutrido equipo de arquitectos fue encabezado por Manuel de SolàMorales y Vicente Manuel Vidal que definieron un conjunto muy integrado en sí mismo, pero descontextualizado con el aspecto formal -no con las variables funcionales- del resto del centro histórico (una de las quejas de los no residentes en él), que tenía por objetivo esencial introducir de forma coherente y ajustadas al sitio -al solar, a su topografía y a su emplazamiento- los conceptos y los aspectos formales de la arquitectura contemporánea en el centro histórico.

Resulta planteamiento muy interesante por cuanto, lejos de priorizar la conservación de lo construido como reflejo del pasado (conservadurismo y priorización del ladrillo), se entiende que lo verdaderamente histórico en el sitio de La Sang es la función residencial, el hábitat obrero, y por ello se busca recuperar esa función, sobre la base de la interpretación moderna de las viviendas obreras, que debían ser atractivas, a las vez que eficientes (conforme con los criterios del diseño racionalista).

Así, de acuerdo con la Urbanística de la Escuela de Barcelona, en la que sobresale las aportaciones teóricas de Solà-Morales (MunizaGA, 2000), la ciudad es un conjunto de arquitectura y no un conjunto de planes administrativos, por eso se enfatiza el papel del proyecto (de ejecución) que es el que permite hacer ciudad, y se relega a un segundo plano, o se obvia, la necesidad de planes, como ocurrió en Alcoy. Del análisis de la evolución urbana de toda ciudad histórica, se comprueba que la ciudad se ha construido a partir de la yuxtaposición de diferentes tipologías, conforme con las demandas sociales y económicas de cada momento. El crecimiento urbano de Alcoy es un proceso continuo, por ello se critica la idea conservacionista de "fosilizarlo" en el tiempo y los excesos del fachadismo historicista (que era dogma oficial cuando se emprende el Plan ARA, al que se volvió a partir de los cambios en los principales agentes sociales de la ciudad).

Se ha señalado que éste autor podía incluirse dentro del ámbito genérico de la arquitectura moderna. No obstante, es preciso indicar que en sus aportaciones critica la estandarización funcional y el desprecio del lugar, de las condiciones 
del sitio- propias del Movimiento Moderno, tanto como otras cuestiones que conducen hacia la banalización del urbanismo. Para Solà-Morales, la Urbanistica actúa a partir del diseño de los espacios públicos (vías, zonas verdes y equipamientos) que deben ser los elementos preponderantes del proyecto, como en el Barri La Sang. La vivienda constituye el segundo elemento complementario de la morfología urbana, diseñada siempre de forma unitaria desde el proyecto. Con la Urbanística se volcaba en Alcoy toda la experiencia de la recuperación de los barrios históricos de Aranjuez y Barcelona: Ciutat Vella, El Raval y La Barceloneta.

El diseño de La Sang comienza por la cuestión de la búsqueda de una escala ajustada al sitio (volumetría y superficie) y de sus relaciones con el centro histórico: proximidad y necesidad de una cierta separación -retranqueos y pasillos verdes, pero no a costa de las comunicaciones: puentes de acceso directo desde La Sang hacia el parque de La Glorieta (peatonales) y hacia las principales vías del centro histórico (rodados) a diferente nivel.

Cuestión esencial ha sido la del análisis de la malla urbana preexistente y de la del contexto. Frente a la solución de la cuadrícula (que se impone en las otras partes del Plan ARA en desarrollo a partir de la dejación de la iniciativa en manos privadas), La Sang sigue las directrices históricas de la malla del callejero preexistente (que orientaba las infraestructuras y los viales), lo que obliga al estudio de diferentes alternativas edificatorias para cada una de las partes del sitio, que cuenta con pendientes de hasta el 19\%, salvadas por graderías, rampas y puentes. Por último, del análisis del "grano de la malla" preexistente, se llega a las dimensiones de las manzanas y calles planeadas para el barrio y, con ellas, a la tipología edificatoria y a las propias viviendas que, en La Sang, buscan vínculos historicistas simbólicos para su contextualización.

El primer enlace con el pasado es que siga siendo un barrio obrero, por ello las viviendas deben ser económicas y de bajo coste de mantenimiento. Las viviendas substituidas eran las conocidas como "cases de clau" (DÁvILA, 1993). En Alcoy, Barcelona y en otras ciudades de vieja industrialización, la partición de las viviendas en habitaciones (quarts) fue común durante el s. XIX, y también la construcción de nuevas alturas desde esos quarts: nuevos quarts añadidos a los preexistentes. La acusada pendiente condicionó los accesos desde la escalera, de forma que no existían los rellanos con dos entradas, sino que las puertas de las viviendas se sucedían en los giros de la escalera a diferentes alturas (estructura helicoidal). Las nuevas viviendas de La Sang siguen esa tradición y mantienen los condicionantes de la pendiente, 
incluso en el interior de las viviendas, con dependencias a diferente altura. Con todo, pese a las referencias historicistas, en algunos detalles de las viviendas se observan claros guiños a la Unité d'habitation de Le Corbusier (distribución, mobiliario mínimo, diferentes niveles, colores y hasta en la numeración de las viviendas).

Se construyeron 144 viviendas, de diferente tamaño $\left(30,60,90\right.$ y $\left.120 \mathrm{~m}^{2}\right)$ conforme con la estructura de la demanda potencial. El precio de mercado en el año 2001 fue de 100.000 pesetas $/ \mathrm{m}^{2}$ (unos $1.200 € / \mathrm{m}^{2}$ aproximadamente a precios constantes), si bien en 2013 se venden a unos $1.000 € / \mathrm{m}^{2}$. El IVVSA tramitaba una subvención a fondo perdido del $10 \%$ del importe. Las viviendas se adjudicaban conforme con la capacidad de renta de los peticionarios y sus posibilidades de afrontar el pago de la hipoteca; esto es, no fueron concebidas como viviendas sociales (tal como las anteriores), aunque el mercado se retrajo por la suposición de que, en efecto, el comprador volvería a verse envuelto en esa matriz social de comportamientos marginales. Los aparcamientos estaban disociados de las viviendas, con un precio entre 500.000 ptas. y 750.000 ptas.

Como en Barcelona, las 15 familias afectadas (muchas viviendas ya estaban desocupadas) fueron realojadas en una promoción de viviendas privada -en el Barrio de la Abastecedora- compradas por el IVVSA que, a su vez, procedía a venderlas a los afectados, que por contrato renunciaban a volver a La Sang, en evidente y modesto proceso de gentrificación, para evitar población no deseada.

En 2001 se entregaba un centenar de viviendas a los vecinos, en acto protocolario que capitalizaba el PP y su alcalde que, conforme con el paternalismo de la tradición franquista, "concedía en nombre del Gobierno del PP la vivienda al feliz agraciado" (que debía pagarla). Ya en esos momentos se apreciaron algunos problemas de construcción (imputados al cambio de empresas constructoras durante el proceso), como humedades, problemas en los cerramientos y acabados defectuosos, pero las quejas de los vecinos no fueron atendidas, entre otras cuestiones porque en las juntas de la comunidad de propietarios, el IVSSA con unas 40 viviendas sin vender mantenía una posición hegemónica.

Finalmente, en 2007, a petición expresas y reiterada del Ayuntamiento y los vecinos, el IVSSA, accedía a estudiar los problemas denunciados, y en 2010 anunciaba que el arreglo integral de La Sang quedaba condicionado al fallo del litigio contra la constructora responsable. Entre tanto, se ha procedido a la reparación parcial de algunos problemas, con soluciones que afectan muy negativamente la imagen del conjunto: como son la eliminación de las cornisas de puertas y ventanas y el anclaje con tornillos de las placas de caliza que forran las fachadas. 
Figura 3. Plan ARA, valoración por colectivos

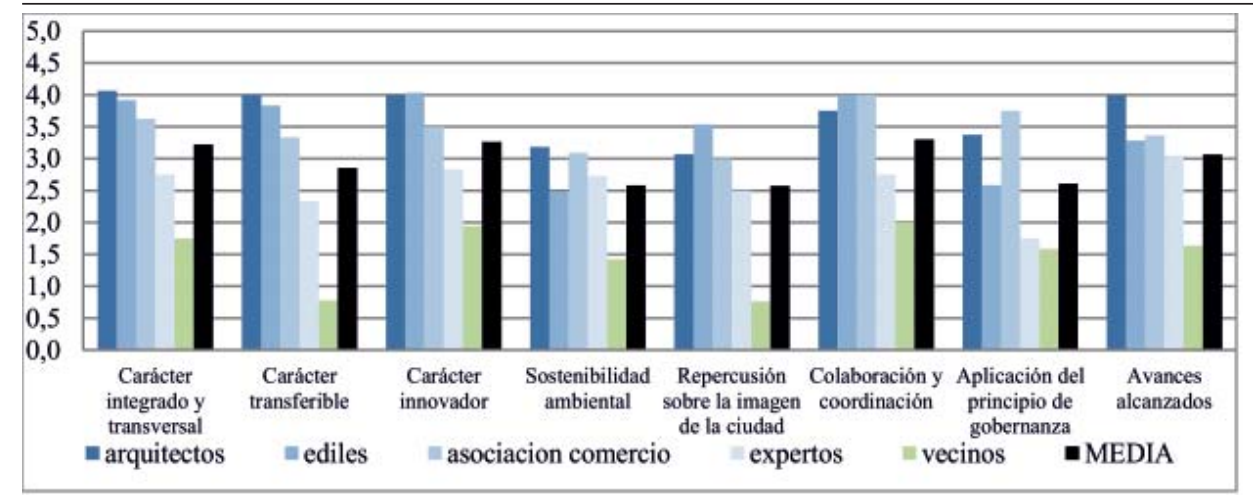

FUENTE: Encuesta 2013 y elaboración propia.

Figura 4. Barri La Sang valoración por colectivos.

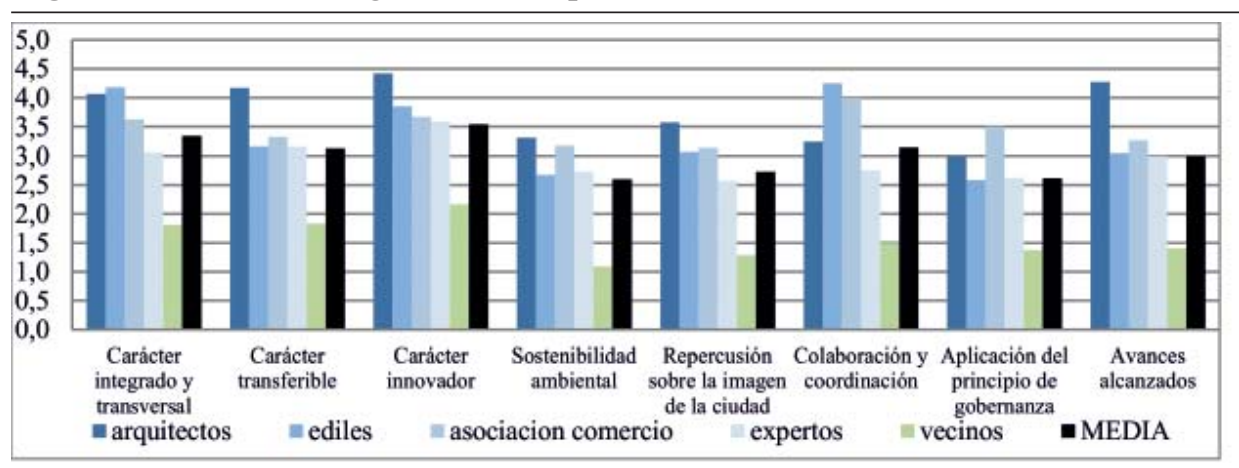

FUENTE: encuesta 2013 y elab. prop

\section{EVALUACIÓN DE LAS ACTUACIONES DEL PLAN ARA}

En el ejercicio de valoración de las actuaciones planeadas y llevadas a cabo, se procedió a un trabajo de entrevistas a diferentes agentes sociales de la ciudad durante el año 2013. Se siguió un formato de entrevistas abiertas, en una primera fase, para luego concretarse en entrevistas cerradas, vía e-mail, con un cuestionario estructurado que suma un total de 50 items, agrupados en ocho grandes apartados: carácter integrado y transversal, carácter transferible, carácter innovador, sostenibilidad ambiental, repercusión en la imagen de la ciudad, colaboración y coordinación interinstitucional, gobernanza y avances alcanzados. A 
los encuestados se les pidió que valorasen entre 0 y 5 cada una de las cuestiones -mínima y máxima valoración-, con el propósito de intentar medir y objetivar su percepción sobre las actuaciones y sus logros, conociendo las limitaciones estadísticas que supone una muestra tan reducida como la manejada. Los entrevistados y encuestados fueron seleccionadas conforme con su conocimiento general de los procesos, su capacidad de identificar aspectos favorables y negativos y de acuerdo con una cierta representatividad social: la muestra se compone de dos arquitectos directamente implicados en el proceso y con trabajo en las áreas afectadas, dos concejales del Ayuntamiento de Alcoy, con responsabilidades muy afines a los procesos analizados, dos asociaciones de comercio (una general y otra radicada en la zona ARA), dos expertos urbanistas, con trabajos científicos sobre la ciudad de Alcoy y dos asociaciones de vecinos de la zona ARA. Se pretendía acotar la información obtenida en las entrevistas e intentar cuantificarla según la valoración de los propios entrevistados.

Figura 5. Plan ARA, valoración media de los criterios analizados (0 mínimo y 5 máximo)

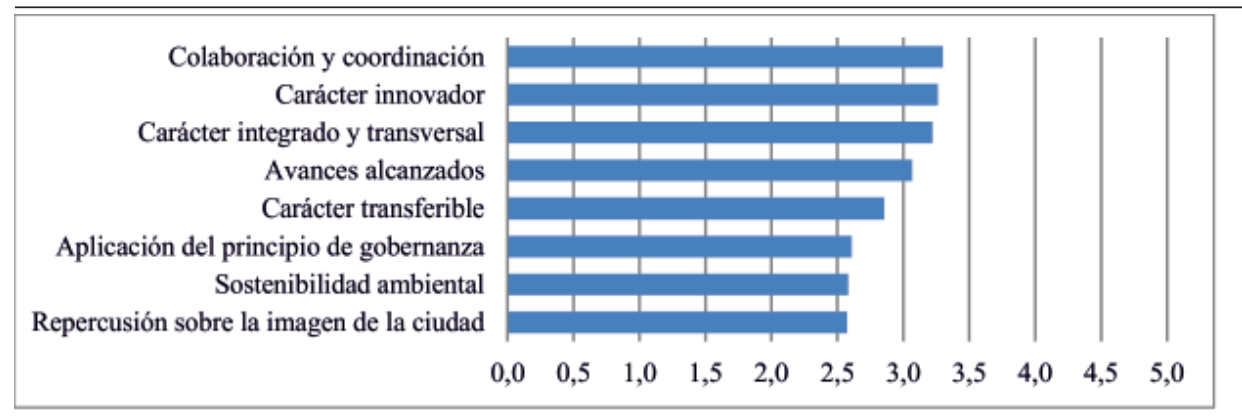

FUENTE: encuesta 2013 y elab. prop.

Figura 6. Barri La Sang, valoración media de los criterios analizados (0 mínimo y 5 máximo)

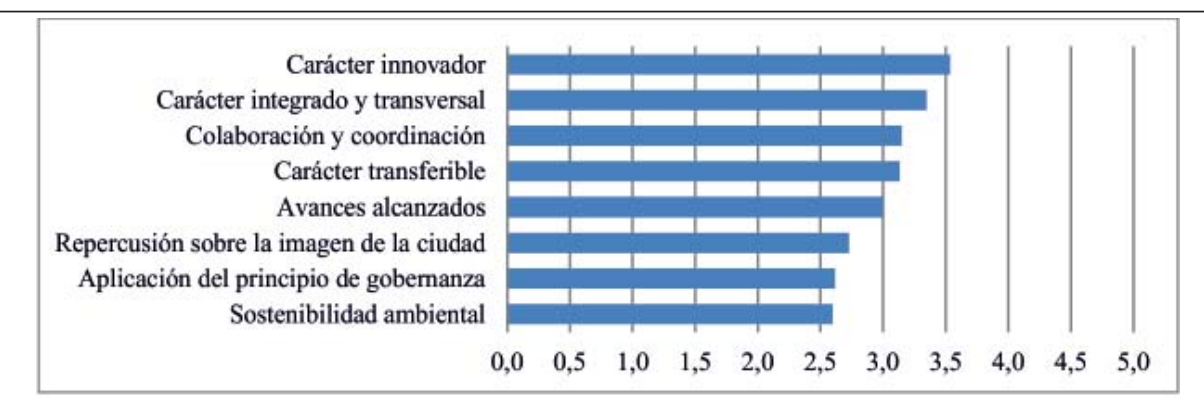

FUENTE: encuesta 2013 y elab. prop. 


\section{IV.1 La opinión de los agentes sociales}

Por lo general, los técnicos comprometidos con el proceso son los que mejor valoran los diferentes ítems, seguidos de los concejales del Ayuntamiento y las asociaciones de comercio. Por el contrario, las asociaciones de vecinos coinciden siempre en la peor valoración. Entre unos y otros, los expertos señalan valoraciones intermedias, que pueden ser debidas a un criterio más objetivo, por alejado (menos implicados), de los aspectos positivos y negativos derivados de las actuaciones. Preguntados por separado para valorar el conjunto de propuestas del Plan ARA y los logros del Barri La Sang (la única concreción fielmente ajustada a las propuestas iniciales), los indicadores de valoración tienden a coincidir, según cada grupo de encuestados y, también, conforme cada una de las ocho grandes variables, aunque en todos los casos, las valoraciones de La Sang son siempre ligeramente más favorables que las del Plan ARA.

Agrupadas por áreas de consenso, los aspectos mejor valorados (por encima de 3 tanto en el Plan ARA, como en La Sang) son la colaboración y coordinación institucional, el carácter innovador y el carácter integrado y transversal de las propuestas. Con un valor intermedio (alrededor de 3) aparecen en ambos casos el carácter transferible y la valoración de los avances alcanzados. Los aspectos peor valorados (próximos al 2,5 en ambos casos) son los referidos a la gobernanza, a la sostenibilidad ambiental y a las repercusiones en la imagen de la ciudad.

La interpretación de esos resultados, junto con los análisis precedentes, ponen de manifiesto que las operaciones del Plan ARA (Barri La Sang incluido) se vivieron en la ciudad como un complejo proceso que implicaba a todas las administraciones públicas (desde el Ministerio de Fomento, hasta el Ayuntamiento, pasando por la Consellería de Urbanismo -COPUT- y el IVVSA), con un evidente carácter transversal, ya que entre sus objetivos se hallaba tanto la cualificación de la escena urbana, como la recuperación de las funciones del centro histórico y la cualificación de la mano de obra hacia actividades terciarias de cierto nivel (equipamientos de formación y conocimiento). En general, se valora todo el paquete de medidas como un conjunto de estrategias muy innovadoras, para revertir la situación de crisis general de Alcoy y de su centro histórico en particular.

El punto más débil se halla en los aspectos relacionados con la gobernanza que, en Alcoy, tienen mucho que ver con la falta de participación pública, la enajenación de las viviendas bajo el pretexto del beneficio común y, sobre todo, por la falta de concreción de muchos de los objetivos físicos (equipamientos y viviendas), después de las tareas de expropiación y expulsión del hábitat. Así, se 
considera que los efectos no son muy beneficiosos para la imagen de la ciudad $\mathrm{y}$, por tanto, no se valora demasiado la posibilidad de que las estrategias puedan ser transferibles a otros barrios de la ciudad o a otras ciudades de características similares.

\section{EL EJEMPLO DEL PLAN ARA EN EL CONTEXTO DE PRÁC- TICAS ESTATALES E INTERNACIONALES SOBRE CENTROS HISTÓRICOS}

Un claro antecedente de las propuestas del Plan ARA se halla en el Plan Especial de Reforma Interior del Casco de Aranjuéz, elaborado por Rafael Moneo y Solà-Morales, con vigencia entre 1981 y 1996 (el Plan ARA y el proyecto de La Sang se presentaban en 1991). En Aranjuez, ambos urbanistas planteaban la hipótesis de que la verdadera conservación de la ciudad radicaba en la identificación de las claves históricas que hicieron posible su configuración, para volver a ponerlas en práctica, puestas al día. Así, se ponía el énfasis en la renovación gradual de todo el espacio histórico: la conservación en Aranjuez, sólo se garantizaba mediante normas que permitiesen construir y que era la continua construcción de la ciudad quien garantizaría su conservación (ECHEvARRIA, 1998). Se entendía que la renovación de la edificación era esencial para conservar el tejido histórico, mantener las funciones de centralidad y revitalizar el espacio. Para ello era fundamental identificar las claves que definieron la tipología de las viviendas en el s. XIX y aplicarlas con criterios del s. XX (tal como en La Sang). Se atacaban los criterios tradicionales para la conservación de los centros históricos, limitados a la catalogación de edificios y a su protección pasiva, con escasas o nulas estrategias de revitalización social y funcional.

El plan de renovación de Aranjuez fue acogido con gran interés por la comunidad científica y controversia por los ciudadanos (vecinos, propietarios y agentes inmobiliarios), casi en la misma medida que luego ocurriría con el Plan ARA y el Barri La Sang en Alcoy, donde se mantenían los criterios, pero con los beneficios de la primera experimentación en Aranjuez que, entre otras cuestiones, resolvía el problema derivado de mantener las manzanas y parcelas históricas, reemplazas en La Sang por una nueva interpretación de la manzana tipológica histórica.

A su vez, La Sang y el Plan ARA servirían de referencias, con sus logros y problemas, para la redacción del proyecto de renovación para el sector central de la ciudad holandesa de Arnhem (2001-2005), afectado por una mala reconstruc- 
ción tras los efectos de la segunda guerra mundial. El Plan Maestro fue encargado también a Solà-Morales, que proponía la recuperación funcional de un barrio decadente sobre un frente fluvial (lo que también remite a Alcoy) con cinco zonas diferenciadas (tal como el Plan ARA) que debían ser desarrolladas por diferentes equipos de urbanistas. Básicamente se trata de esponjar el viejo sector urbano, rediseñar los espacios públicos y renovar los edificios, todo de forma tan ambiciosa y costosa como en Alcoy y, también, sin demasiado respaldo ciudadano ante cambios tan radicales de la fisonomía urbana.

Más sutil sería la herencia de estos criterios en la rehabilitación (ya no renovación) del Barri del Carmé en Reus, proyecto de Solà-Morales ejecutado entre 2004-2010. Barrio obrero en proceso de degradación y con graves problemas sociales, para el que las mejoras de accesibilidad y dotaciones públicas se realizarían ya con una escala de mucho mayor detalle, atendiendo a la conservación de la trama existente y a la reutilización de los edificios fabriles para usos terciarios y sociales.

\section{CONCLUSIONES}

En general, las propuestas del Plan ARA (con La Sang) se incardinan en el contexto de las políticas de renovación urbana acometidas en la Europa más desarrollada en los años 1980, con especial significación en las ciudades reconstruidas de urgencia tras la segunda guerra mundial, con técnicas y materiales deficientes que experimentaban ya un claro deterioro físico. Como en Alcoy, esas viviendas fueron moradas de obreros y, paulatinamente, de los segmentos sociales más depauperados. Pero por su renta de situación, y conforme con las grandes estrategias urbanas de cualificación de sus centros, las ciudades buscaron reconvertir esos viejos espacios en nuevas zonas de hábitat más cualificado, necesario para acompañar estrategias de recuperación terciaria y, a veces, hasta turísticas: barrio de negocios, barrio asociado a un turismo cultural, nuevas actividades empresariales ligadas al conocimiento y a la tecnología, tal como se proponía para Alcoy.

En todas partes se encontraron con la oposición más o menos intensa de los vecinos, reticentes a cambiar sus modos de vida o a ser directamente desplazados, o a entrar sin quererlo en el mercado inmobiliario. Tales quejas hallaron amparo en las instituciones y en los profesionales del urbanismo, y quedaron plasmadas, en Alemania, en las propuestas de la Internationale Bau Ausstellung, exposición internacional de arquitectura realizada entre 1976 y 1987, que comenzó siendo una gran operación paralela de demolición y renovación de los barrios centrales y acabó incorporando una mayor sensibilidad hacia el espacio construido, fomen- 
tando la participación de los residentes (inquilinos y propietarios) para concretar con ellos el grado de la reforma que era posible (Rincón, 2005).

En Alcoy, la abrupta interrupción de las propuestas ha impedido observar si se hubiese dado un giro hacia una mayor participación ciudadana -gobernanza-, que parece una de las principales carencias (o mala práctica) denunciada por los vecinos y mal valorada por los demás colectivos entrevistados y encuestados. El cambio en el paradigma formal y la orientación casticista de las nuevas edificaciones también afectan al carácter innovador de las propuestas originales no ejecutadas. Incluso la buena valoración del carácter integrado y transversal (objetivos formales, sociales y funcionales) se ve afectada por el cambio de rumbo neoliberal y la búsqueda de nuevas rentabilidades más económicas que sociales (cesión a la iniciativa privada). Es más, uno de los aspectos mejor valorados, el de la colaboración y coordinación entre las administraciones implicadas, con ser cierto en la primera etapa, se vio truncado a partir de 1999 con la aparición de gobiernos local y regional de diferente signo político, evidenciando que, más que colaboración entre administraciones, lo que de verdad existió fue colaboración entre políticos afines.

Por todo ello, la valoración general de los logros alcanzados es moderada y baja la referida a las repercusiones sobre la imagen de la ciudad, condicionada tanto por las demoras en las ejecuciones, las demoliciones sin posterior edificación y, en la última etapa, la simple sustitución de viejas viviendas por nuevas viviendas historicistas, que mantienen las mismas altas densidades e incluso aumentan las volumetrías. Precisamente la opción criticada por Solà-Morales (1974) en Barcelona: remodelación capitalista o desarrollo urbano en el sector de la Ribera Oriental.

Es muy posible que, pese a las carencias señaladas por los encuestados (ejemplos de malas prácticas) de haberse ejecutado en su totalidad el Plan ARA, conforme con los objetivos iniciales, la percepción ciudadana sería mucho más positiva y más sentidos los beneficios para la recuperación de las funciones de centralidad de los barrios históricos. Así, la transferibilidad de las propuestas iniciales siguen siendo válidas, como demuestra su aplicación en otras ciudades españolas y europeas, bien que con el conocimiento añadido derivado de cada una de las intervenciones -todas de fuerte base teórica, que fueron sumando conocimientos empíricos a partir de la experimentación en cada ámbito concreto-. Quizá el aspecto más condicionante -y ambivalente- ha sido el de la excesiva dependencia de las relaciones políticas de afinidad y esa puede ser la principal lección que aporta el Plan ARA. 


\section{BIBLIOGRAFÍA}

Burriel de Orueta, E. (2009): "La planificación territorial en la comunidad valenciana (1986-2009)”, Scripta Nova, Vol. XIII, núm. 306. En línea: http://www.ub.edu/ geocrit/sn/sn-306.htm consultado el 14/08/2013

Coput (1991): Arquitectura i Rehabilitació d'Alcoi. ARA, Valencia, Consellería d'Obres Públiques, Urbanisme i Transports -COPUT- $32 \mathrm{pp}$.

DÁvila Linares, J.M. (1993): Alcoy: desarrollo urbano y planeamiento, Alicante, Universidad de Alicante, $198 \mathrm{pp}$.

ECHEVARRIA, J.J. (1998): “La experiencia de la aplicación de la Ordenanza para el casco histórico: origen, desarrollo y perspectivas", Urban, $\mathrm{n}^{\mathrm{0}} 2,136-145$

Gaja DíAz, F. (2001): Intervenciones en centros históricos de la Comunidad Valenciana, Valencia, COPUT, $283 \mathrm{pp}$.

Generalitat de Catalunya (2004): Reus. Barrio de El Carme. En línea: http://www20. gencat.cat/portal/site/territori/ consultado el 2/08/2013

Munizaga Vigil, G. (2000): Diseño urbano. Teoría y Método, México, Alfaomega, 345 pp.

Ponce, G. (2012): “De casco viajo a centro histórico: la recuperación integrada y funcional de los barrios centrales de la ciudad histórica", Gestión del patrimonio arquitectónico, cultural y medio ambiental. Enfoques y casos prácticos, México-Alicante, UAM-UA, 61-84

Ponce, G., DÁvila, J.M., Moltó, E. (2011): "Los paisajes industriales de l'Alcoià”, Paisajes y Geografía en tierras alicantinas, Alicante, AGE, UA, 7-73

RAmíREz, C. (1997): “Algunos problemas en la aplicación de la Ordenanza de Renovación del Plan Especial de Aranjuéz de 1981", Urban, n 2, 162-166

RinCón, P. (2005): “Ciudad y vivienda en el siglo XX en Alemania”, Urbanismos, no 3, Universidad Nacional de Colombia, 176-183

SAINz GuTiÉRrez, V. (2006): El proyecto urbano en España: génesis y desarrollo de un urbanismo de los arquitectos, Sevilla, Junta de Andalucía-Universidad de Sevilla, $250 \mathrm{pp}$.

Fernández Salinas, V. (1994), "Los centros históricos en la evolución de la ciudad europea desde los años setenta", Eria, 121-131

SERT, J.Ll., (1955): “Centros para la vida de la comunidad”, El corazón de la ciudad. Por una vida más humana de la comunidad, (CIAM 8, Hoddesdon, 1951), Barcelona. En línea: http://www-etsav.upc.es/personals/monclus/tesauro.htm , consultado el 24/07/2013

SindicATURA DE Comptes (2001-2006): informes. En línea: http://www.sindicom.gva.es/ web/informes.nsf, consultado el 17/07/2013

Solà-Morales, M. de y otros (1974): Barcelona: remodelación capitalista o desarrollo urbano en el sector de la Ribera Oriental, Barcelona, G. Gili, 79 pp.

SolÀ-Morales, M. de (1997): Las formas del crecimiento urbano, Barcelona, UPC, 196 pp. 
Solà-Morales, M. de y otros (1999): El projecte urbà, una experiència docent, Barcelona, UPC, $273 \mathrm{pp}$.

Torroja, J.A. (1989): Plan General de Ordenación Urbana de Alcoy, anexo 1, s/pp.

Urban Progress Studio (2001-2009): ARNHEM RIJNBOOG, Urban Plan and Quality Team. En línea: http://www.urbanprogress.com/rijnboog2/, consultado el $6 / 08 / 2013$ 